Linköping Studies in Science and Technology.

Dissertation no. 1649

\title{
Improved Methods for Characterization of Protein Dynamics by NMR spectroscopy and Studies of the EphB2 Kinase Domain
}

Alexandra Ahlner

Molecular Biotechnology

The Department of Physics, Chemistry and Biology

Linköping University

Linköping, Sweden 
During the course of the research underlying this thesis, Alexandra Ahlner was enrolled in Forum Scientium, a multidisciplinary doctoral program at Linköping University, Sweden.

Copyright (C) Alexandra Ahlner, unless otherwise noted.

Printed by LiU-Tryck, Linköping 2015.

Improved Methods for Characterization of Protein Dynamics by NMR spectroscopy - and Studies of the EphB2 Kinase Domain

Alexandra Ahlner

ISBN 978-91-7519-103-4

ISSN 0345-7524

Linköping Studies in Science and Technology.

Dissertation no. 1649 
Till Viktor och Livia 


\section{Abstract}

Proteins are essential for all known forms of life and in many lethal diseases protein failure is the cause of the disease. To understand proteins and the processes they are involved in, it is valuable to know their structures as well as their dynamics and interactions. The structures may not be directly inspected because proteins are too small to be visible in a light microscope, which is why indirect methods such as nuclear magnetic resonance (NMR) spectroscopy have to be utilized. This method provides atomic information about the protein and, in contrast to other methods with similar resolution, the measurements are performed in solution resulting in more physiological conditions, enabling analysis of dynamics. Important dynamical processes are the ones on the millisecond timeframe, which may contribute to interactions of proteins and their catalysis of chemical reactions, both of significant value for the function of the proteins.

To better understand proteins, not only do we need to study them, but also develop the methods we are using. This thesis presents four papers about improved NMR techniques as well as a fifth where the kinase domain of ephrinB receptor 2 (EphB2) has been studied regarding the importance of millisecond dynamics and interactions for the activation process. The first paper presents the software COMPASS, which combines statistics and the calculation power of a computer with the flexibility and experience of the user to facilitate and speed up the process of assigning NMR signals to the atoms in the protein. The computer program PINT has been developed for easier and faster evaluation of NMR experiments, such as those that evaluate protein dynamics. It is especially helpful for NMR signals that are difficult to distinguish, so called overlapped peaks, and the software also converts the detected signals to the indirectly measured physical quantities, such as relaxation rate constants, principal for dynamics. Next are two new versions of the Carr-Purcell-Maiboom-Gill (CPMG) dispersion pulse sequences, designed to measure millisecond dynamics in a way so that the signals are more separated than in standard experiments, to reduce problems with overlaps. To speed up the collection time of the data set, a subset is collected and the entire data set is then reconstructed, by multi- 
dimensional decomposition co-processing. Described in the thesis is also a way to produce suitably labeled proteins, to detect millisecond dynamics at $\mathrm{C} \alpha$ positions in proteins, using the $\mathrm{CPMG}$ relaxation dispersion relaxation experiment at lower protein concentrations. Lastly, the kinase domain of EphB2 is shown to be more dynamic on the millisecond time scale as well as more prone to interact with itself in the active form than in the inactive one. This is important for the receptor function of the protein, when and how it mediates signals.

To conclude, this work has extended the possibilities to study protein dynamics by NMR spectroscopy and contributed to increased understanding of the activation process of EphB2 and its signaling mechanism. 


\section{Populärvetenskaplig sammanfattning}

Proteiner är livsviktiga i allt levande vi känner till. Vid många sjukdomar, som till exempel cancer, är det ofta på proteinnivå det blivit fel. För att förstå proteiner och exempelvis kunna utveckla mediciner behöver man bland annat veta hur proteinerna ser ut men också hur de rör sig och interagerar. Enstaka proteiner är alldeles för små för att synas i ens det bästa ljusmikroskop och indirekta metoder så som kärnmagnetisk resonansspektroskopi (NMR-spektroskopi) får istället användas. NMR-mätningar sker i lösning, till skillnad från andra metoder där information på atomnivå erhålls. Detta innebär mer fysiologiska förhållanden och framförallt fördelar när proteinets rörelser ska studeras. Av dessa rörelser sker några viktiga på millisekundskalan, till exempel proteininteraktioner och proteinkatalys av kemiska reaktioner.

Det räcker inte bara med att forska på proteinerna utan metoderna som används för att studera dem måste också utvecklas och förfinas. Denna avhandling presenterar metodutvecklande artiklar inom NMR-spektroskopi tillsammans med en artikel där några av dessa metoder har använts för att undersöka dynamik och interaktioner hos kinasdomänen av ephrinB receptor 2 (EphB2). Först beskrivs ett datorprogram (PINT), där en specifik klass av NMR-experiment utvärderas så att problemen med signaler som är svåra att separera från varandra minskar. Dessutom omvandlar programmet de mätta parametrarna till de indirekta storheter man vill bestämma. Datorprogrammet COMPASS är ett interaktivt program som kombinerar statistik och en dators räkneförmåga med flexibiliteten och erfarenheten hos användaren till att förenkla tilldelandet av NMR-signalerna till atomerna i proteinet. I avhandlingen redogörs också för ett experiment där millisekunddynamik i proteiner studeras, så att signalerna separeras mer än i de experiment som tidigare gjorts. För att experimentet inte ska ta orimligt lång tid används en metod där inte alla experimentpunkter mäts, utan istället rekonstrueras i efterhand. Den sist presenterade metoden redogör för 
hur proteiner kan framställas för specifika millisekundsdynamikmätningar vid lägre proteinkoncentrationer. Slutligen beskrivs hur kinasdomänen av EphB2 blir mer dynamisk på millisekundskalan och lättare binder till sig själv när den aktiveras. Detta är viktigt för EphB2s receptorfunktion, det vill säga hur och när proteinet ska förmedla signaler.

Sammanfattningsvis har detta arbete bidragit till att öka möjligheterna att studera proteindynamik och dessutom medverkat till att utvidga förståelsen av hur EphB2 aktiveras och deltar i signalering. 


\section{List of publications}

\section{Publications included in thesis}

\section{Paper I}

Fast and Accurate Resonance Assignment of Small-to-Large Proteins by Combining Automated and Manual Approaches

Markus Niklasson, Alexandra Ahlner, Cecilia Andresen, Joseph A. Marsh and Patrik Lundström.

PLOS Computational Biology, 2015; 11(1)

\section{Paper II}

PINT: a Software for Integration of Peak Volumes and Extraction of Relaxation Rates

Alexandra Ahlner, Mats Carlsson, Bengt-Harald Jonsson and Patrik Lundström.

Journal of Biomolecular NMR, 2013; 56(3)

\section{Paper III}

Measurements of Protein Backbone ${ }^{13} \mathrm{CO}$ and ${ }^{15} \mathrm{~N}$ Relaxation Dispersion at High Resolution

Alexandra Ahlner, Maxim Mayzel, Patrik Lundström and Vladislav Y. Orekhov.

In manuscript

\section{Paper IV}

Fractional Enrichment Using $\left[2-{ }^{13} \mathrm{C}\right]$-Glycerol as the Carbon Source Facilitates Measurements of Excited State ${ }^{13} \mathrm{C} \alpha$ Chemical Shifts with Improved Sensitivity

Alexandra Ahlner, Cecilia Andresen, Shahid N. Khan, Lewis E. Kay and Patrik Lundström.

Submitted 


\section{Paper V}

Conformational Dynamics and Multimerization of Active Forms of the EphrinB Receptor 2 Kinase Domain

Alexandra Ahlner, Shahid N. Khan, Julie D. Forman-Kay, Frank Sicheri and Patrik Lundström.

In manuscript

\section{Author's contribution}

\section{Paper I}

Developed and designed large parts of the program COMPASS, expressed and purified a portion of the protein samples used for validation, performed and evaluated experiments for validation, tested and troubleshot the program and wrote the paper together with M.N. and P.L.

\section{Paper II}

Participated in the development of the program PINT, expressed and purified the protein samples used for validation, performed and evaluated experiments for validation, tested and troubleshot the program and wrote the paper together with P.L.

\section{Paper III}

Expressed and purified one of the protein samples used, evaluated most NMR data and wrote paper together with the other authors.

\section{Paper IV}

Evaluated NMR experiments and wrote the paper together with P.L.

\section{Paper V}

Designed some of the genes used to express the proteins, expressed and purified most of the protein samples, suggested, performed and evaluated all NMR and AUC experiments, wrote the paper. 


\section{Publications not included in thesis}

Isotope labeling methods for large systems

Patrik Lundström, Alexandra Ahlner, Annica T. Blissing.

Advances in experimental medicine and biology, 2012; 992 (Review)

Isotope labeling methods for relaxation measurements

Patrik Lundström, Alexandra Ahlner, Annica T. Blissing.

Advances in experimental medicine and biology, 2012; 992 (Review)

Protein conformational exchange measured by ${ }^{1} \mathbf{H} \mathbf{R}_{1 \rho}$ relaxation dispersion of methyl groups

Ulrich Weininger, Annica T. Blissing, Janosch Hennig, Alexandra Ahlner, Zhihong Liu, Hans J. Vogel, Mikael Akke, Patrik Lundström.

Journal of Biomolecular NMR, 2013; 57(1) 


\section{Acknowledgements}

Det är mycket som krävs för att kunna bli doktor och ett är i alla fall säkert, jag hade aldrig klarat mig såhär långt ensam.

\section{Tack!}

Patrik, för att jag fick doktorera för dig, för allt jag lärt mig och för alla gånger du tagit dig tid. Nalle, framförallt för inspirerande samtal och för att jag alltid lämnat möten med dig och känt mig intelligent och kompetent.

Markus, för hjälpen med framsidan och korrekturläsning, för alla intressanta diskussioner, för att vi är så olika och för att du alltid är beredd att lära dig och mig nya saker. Cissi, för att du alltid har tid och kunskap att hjälpa till och alltid är så positiv. Annica, för trevligt resesällskap, många välbehövliga fikan och givande samtal. Elin, för att du förde in HU-tankar till vårt labb och för alla delade laborationssorger och -bedrövelser. Ivana, för att du alltid är så glad, vi saknar dig på kontoret.

Shahid, for helping out in the EphB2 and ${ }^{13} \mathrm{C} \alpha$ labeling projects. Alexander L, för hjälp med EphB2-projektet.

Maxim, for all your time and your patience. Cecilia P, Göran and Vladislav for assistance at Swedish NMR center in Gothenburg.

All collaborators, for all your time, expertise, inspiration and valuable input.

Maria S, för att du introducerade mig till strukturbiologi. Utan biomätteknikkursen tror jag aldrig att jag hade skrivit den här avhandlingen. Lasse, för en bra introduktion till röntgenkristallografi och givande diskussioner. Magdalena, för småprat och stöd. Uno W, för att du lyssnat.

Patricia, för att du är en sådan fantastisk lyssnare och vän. Madhan, for always helping out, bringing laughter and good humor. Sara $\mathbf{H}$, för sunt förnuft, hjälp och trevliga samtal. Jutta, för stöd, uppbackning och promenader. Sara N, för stöd och vänskap. Sofie; när jag blir stor ska jag bli som du! Gunnar B, för helgsällskap under slutspurten. Maria L, för att du bryr dig. Lotta, för din energi och ditt engagemang. 
Alla medlemmar i Forum Scientium, för intressanta och givande studiebesök och konferenser och för alla möten då vi delat kunskap och erfarenheter.

Alexander S, Amélie, Anna-Lena, Daniel K, Daniel S, Ina, Jonas, Karin, Leffe, Linda, Maria J, Maria T, Mikaela, Rozalyn, Therése och Veronica för alla trevliga luncher, fikan, all hjälp och givande diskussioner.

Övriga kollegor på Linköpings Universitet som hjälpt mig med stort och smått.

Mina vänner utanför arbetet som fått mig att tänka på annat.

Tuija och Gunnar, för alla helger, framförallt i Åmmeberg. Ni älskar Livia lika mycket som hon älskar er och om det gläder mig eller er mest är frågan.

Rebecca, för att du är så generös med allt och för att det inte finns någon som har sådan bra humor som du. Gustaf; framförallt för alla småbesök och alla gånger du lekt med Livia. Mamma och pappa; hur tackar man sina föräldrar tillräckligt? Jag vet inte, men ni hjälpte mig lägga grunden för min nyfikenhet och ni finns alltid där.

Viktor, för allt stöd och alla genomläsningar av mina texter, för att du är en lika stor nörd som jag, för att du tar så bra hand om vår dotter och för att du älskar mig som jag är. Livia, för att du alltid får mig att skratta, för att du får mig att förstå vad som verkligen är viktigt här i livet och för att du är världens godaste. 


\section{Contents}

Abstract $\quad$ v

Populärvetenskaplig sammanfattning vii

List of publications $\quad$ ix

Acknowledgements xiii

1 Proteins 1

1.1 Protein Structure . . . . . . . . . . . . . . . . . . . . 1

1.2 Protein Dynamics . . . . . . . . . . . . . . . . . . 3

1.2 .1 Time Scales . . . . . . . . . . . . . . . . . . . 3

1.2 .2 Energy Landscapes . . . . . . . . . . . . . . . . . 3

1.2 .3 Chemical Exchange . . . . . . . . . . . . . 4

1.3 Enzymes . . . . . . . . . . . . . . . . . . . . . . . 4

1.3 .1 Kinases . . . . . . . . . . . . . . . . 4

1.4 Receptors . . . . . . . . . . . . . . . . 6

1.4.1 Eph Receptors and Ephrins . . . . . . . . . 6

2 Studying Proteins 9

2.1 Structural Biology . . . . . . . . . . . . . . . . . . . . 9 9

2.1.1 X-ray Crystallography . . . . . . . . . . . . . . 9 9

2.1.2 Nuclear Magnetic Resonance Spectroscopy . . . . . . . 10

2.2 Analytical Ultracentrifugation . . . . . . . . . . . . . . 10

3 Nuclear Magnetic Resonance Spectroscopy 13

3.1 Fundamentals of NMR Spectroscopy . . . . . . . . . . . 13

3.1.1 Larmor Frequency . . . . . . . . . . . . . . . . 14

3.1 .2 Chemical Shifts . . . . . . . . . . . . . . . . . 14

3.1 .3 NMR Experiments . . . . . . . . . . . . . . . . 15

3.1 .4 Spin Interactions . . . . . . . . . . . . . . . 16

3.1.5 Multidimensional Experiments . . . . . . . . . . 20 
3.1.6 Heteronuclear Experiments . . . . . . . . . . . . 20 20

3.1 .7 Resonance Assignments . . . . . . . . . . . . . . . . 22

3.1 .8 Isotopic Labeling . . . . . . . . . . . . . . . . . . 22

3.2 Relaxation . . . . . . . . . . . . . . . . . . . 23

3.2.1 Pico-Nanosecond Time Frame Experiments . . . . . 25

3.2 .2 Relaxation and Chemical Exchange . . . . . . . . . . . 26

$3.3 \quad$ Specific Isotopic Labeling . . . . . . . . . . . . . . . . . . 31

3.3.1 Amino Acid Synthesis in E. coli . . . . . . . . . . . 31

3.4 NMR Studies of Large Proteins . . . . . . . . . . . . . . . . . 32

3.4 .1 TROSY . . . . . . . . . . . . . . . . . . . 32

3.4 .2 Deuteration . . . . . . . . . . . . . . . 33

3.5 Fast Sampling Techniques . . . . . . . . . . . . . . . . . 34

3.5 .1 Non-Uniform Sampling . . . . . . . . . . . . . . 34

4 Data Analysis 35

4.1 Data Fitting . . . . . . . . . . . . . . . . . . 35

4.2 Error Estimation . . . . . . . . . . . . . . . . . . 36

4.2 .1 Error Propagation . . . . . . . . . . . . . . 37

4.3 Evaluating Fits . . . . . . . . . . . . . . . . . . . 37

$4.3 .1 \quad F$-Test . . . . . . . . . . . . . . . . . 38

4.3.2 $t$-Test of a Correlation Coefficient . . . . . . . 38

5 Summary of My Work 41

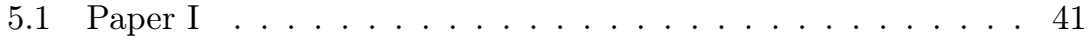

5.2 Paper II . . . . . . . . . . . . . . . . . . . . . . . . . . . . . 42

5.3 Paper III . . . . . . . . . . . . . . . . . . . . . . . . . 43

5.4 Paper IV . . . . . . . . . . . . . . . . . . . . . . . . . . 44

5.5 Paper V . . . . . . . . . . . . . . . . . . . 44

6 Conclusions and Perspectives $\quad 47$

$\begin{array}{ll}\text { References } & 51\end{array}$

7 Papers $\quad 59$

Paper I . . . . . . . . . . . . . . . . . . . . 61

Paper II . . . . . . . . . . . . . . . . . . . . . . . . . . . . . . . 79

Paper III . . . . . . . . . . . . . . . . . . . . . . . 93

Paper IV . . . . . . . . . . . . . . . . . . . . . 111

Paper V . . . . . . . . . . . . . . . . . 125 


\section{Chapter 1}

\section{Proteins}

Proteins are versatile molecules that are present in all life forms. They build up our muscles, hair and nails and also facilitate almost all processes in the body. They transport oxygen in our blood, send and receive signals throughout the body, copy and translate our DNA and assist in the sensing of our environment. They are involved in everything.

\section{$1.1 \quad$ Protein Structure}

Proteins are polymers consisting of amino acids of which most species use twenty different ones. The amino acids are connected through a peptide bond one after another, as beads on a string, and therefore proteins are also called polypeptides. Figure 1.1 shows a schematic picture of a polypeptide chain composed of three amino acids from a protein. The nuclei denotation will be used throughout this thesis. Usually what makes a protein functional is the way the one dimensional bead string folds into a three-dimensional structure. The protein structure is divided into four levels. The primary structure is the order in which the amino acid residues are linked together. The secondary structure for each residue is defined by two bond angles, $\psi$ and $\phi$, in the polypeptide chain. The two major secondary structure elements are $\alpha$-helix, where the polypeptide chain is twisting around its own axis and $\beta$-sheet where the polypeptide moves back and forth in flat structures. Other forms of distinct helices, sheets and turns, that link the sheets, also exist. Unfolded structures are called random coil, which may also somewhat carelessly be denominated structures not well defined. For examples on illustrations of these structures see figure 1.2. Tertiary structures are how the secondary structure motifs are positioned relative each other and here the connecting loops play very important roles. It is common that the activity of a protein is positioned in the loops [1] and that the secondary 
<smiles>[R][Z8][C](NC(=O)[C]([B][R])NC(=O)[C](NC)[Ga][R])C(C)=O</smiles>

Figure 1.1: Schematic picture of three amino acids in a polypeptide chain. $R_{x}$ indicates different side chains depending on the type of residue. Hydrogen atoms are excluded for simplicity. The notation of the nuclei used in the picture are the conventional ones used in the rest of the thesis.

structure elements are the skeleton positioning the loops correctly. Quaternary structure is when the protein consists of many polypeptide chains that make up different subunits and how these are located relative each other. A protein composed of two different polypeptide chains is called a heterodimer, whereas a homodimer has two copies of the same polypeptide chain. A protein with three peptide chains is named a trimer, and one with four chains a tetramer. If it is known that the protein consists of multiple polypeptide chains but it is unknown or undefined how many, the protein may be called an oligomer or a multimer.
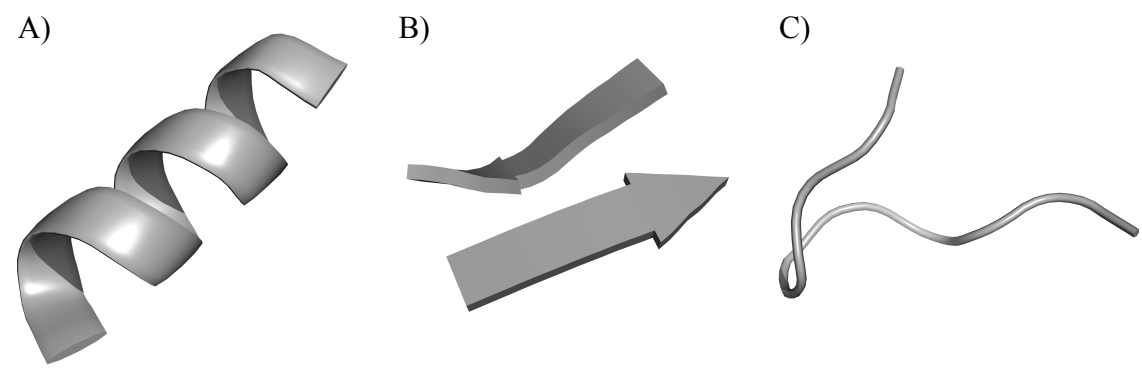

Figure 1.2: Cartoon representations of secondary structure elements A) $\alpha$-helix, B) $\beta$-sheet and C) random-coil. 


\subsection{Protein Dynamics}

Proteins are in constant movement. Free in solution they are tumbling around their own axes and at the same time diffusing around in the solution. All atoms in the protein are also moving relative each other: stretching and bending the bonds between the atoms and sometimes more synchronized moving of a few residues or a whole domain simultaneously. The motions of the protein are called protein dynamics and they occur on different time scales ranging from picoseconds to days or years. It has been more and more obvious in the past decades that the dynamics are important for protein behavior. To understand protein function it is essential to not only study their structures but to also investigate their dynamics.

\subsubsection{Time Scales}

Different dynamical processes occur on different time scales and the time constant may reveal the type of process but also aids in choice of experimental setup. The time constant describes the average time between two repetitions of a specific process, for example binding and release of a ligand. The time scale can also be specified as a rate, which instead would give how many times per second the movement is repeated. For example a millisecond motion that has the time constant of $20 \mathrm{~ms}$ has the rate $50 \mathrm{~s}^{-1}$. The smallest motions are the fastest and these may report on how flexible different parts are relative each other. These motions are in the pico-nanosecond time frame. The first and last couple of residues in a protein almost always are more flexible than the rest but also loops are generally flexible. Motions on the micro-millisecond time scale are usually larger conformational changes that require reorganization of residues or bonds. Example of processes that takes place on this time scale is ligand binding, protein-protein interaction and enzymatic catalysis $[2-5]$.

\subsubsection{Energy Landscapes}

The energy landscape describes the energy of every protein configuration. The structure of the protein is usually described by the protein configuration with the globally lowest energy, but it may also be kinetically driven and therefore decided by a stable configuration that is fastest to form [6]. The energy landscape also describes if the global minimum is smooth and deep, the protein sample has one dominating configuration, or if the global minimum are surrounded by local minima and the protein sample has an ensemble of different configuration states. Depending on the activation energy between the states, which is the size of the barrier separating them, a single protein is trapped in one configuration (high barrier) or changes between 
different configurations (low barrier). Whenever the system is changed, for example if the temperature is increased, the energy of the protein also increases and the protein explores more of the energy landscape. The landscape may also be changed, by for example adding a ligand or changing the buffer. Some of the dynamical processes are small motions in the landscape, while others changes the protein more dramatically.

\subsubsection{Chemical Exchange}

One important dynamic process in the millisecond time scale is chemical exchange, when a molecule undergoes a process that changes its chemical shifts (described in 3.1.2). Most important for this thesis are conformational exchange [2], where the protein undergoes structural reorganization, and the exchange process between free protein and protein bound to ligand [7]. The first process may be described by the equilibrium reaction

$$
[P] \rightleftharpoons\left[P^{*}\right]
$$

where $[P]$ is the concentration of protein in its ground state and $\left[P^{*}\right]$ is the concentration of the protein in the excited state. The ground state is the most thermodynamically stable conformation of the protein and the excited state is the conformationally changed protein, which has higher energy. The second process may be described by the equilibrium equation

$$
[P]+[L] \rightleftharpoons[P L]
$$

where $[P]$ is the concentration of free protein, $[L]$ is the concentration of free ligand, which may be a small molecule, another protein or the protein itself, and $[P L]$ is the concentration of ligand bound to protein.

\section{$1.3 \quad$ Enzymes}

As previously mentioned proteins have many different functions but most relevant for this thesis are enzymes and receptors. Enzymes are macromolecular catalysts, mostly of them proteins. They speed up the reaction time of chemical reactions, by lowering the activation energy [8], which is essential to sustain life. It is common with enzymatic rate enhancement of $10^{10}-10^{23}$ times [9]. As all catalysts they are not consumed by the reaction they catalyze.

\subsubsection{Kinases}

Kinases are proteins that catalyze the phosphorylation of other proteins. Phosphorylation is extensively used as signal regulation in the eukaryotic 
cell [10] and the human genome codes for over 500 different kinases, corresponding to approximately $2 \%$ of all human genes [11]. The kinases have evolved to be not as catalytically efficient as possible but to be easily and precisely regulated [12]. The process of phosphorylating a protein involves the transfer of a phosphate group from adenosine triphosphate (ATP) to a hydroxyl group on the target protein. The kinases are divided into serine/threonine, histidine and tyrosine kinases depending on the phosphorylated residue on the substrate. All kinases use one or two $\mathrm{Mg}^{2+}$ ions as cofactor, facilitating catalysis. The structure of the kinase domain is conserved between kinases, probably due to the conserved catalyzing processes [13], but normally there are domains other than the kinase domain that are very different. The kinase domain consists of two lobes: the Nlobe and the C-lobe separated by the catalytic cleft in-between. The kinase domain of the kinase with most published structures is illustrated in figure 1.3. The N-lobe consists of a twisted antiparallel $\beta$-sheet, one longer $\alpha$ helix, loops and smaller structure elements. The C-lobe is mostly $\alpha$-helical with a small $\beta$-sheet. A few different structure elements have been shown to be especially important for the kinase activity. Located in the N-lobe

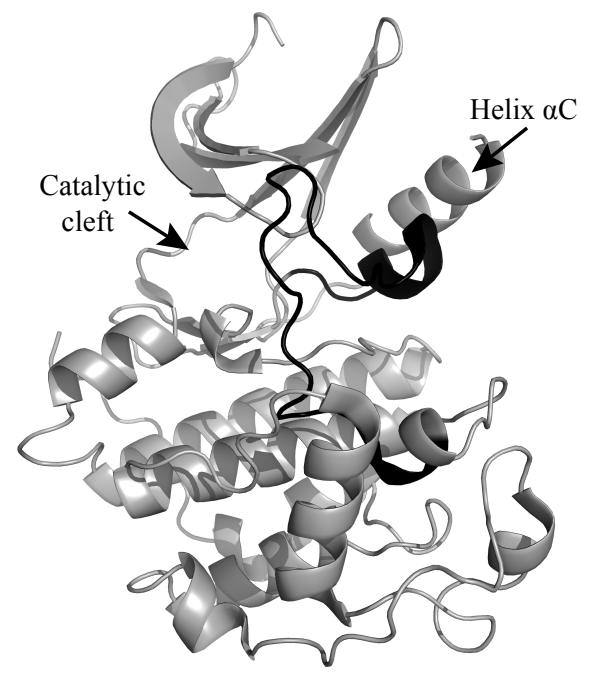

Figure 1.3: A cartoon picture of one of the crystal structure of the CDK2 kinase (PDB:ID 4EK3), the kinase with most published structures. At the top is the N-lobe and the C-lobe is at the bottom. Indicated in the picture are also the catalytic cleft and the allosteric important structure helix $\alpha \mathrm{C}$. The activation segment is colored black. 
are; the highly dynamic allosteric regulator, the helix $\alpha \mathrm{C}$ and the flexible glycine rich loop, which helps to correctly position ATP. In the C-lobe; the activation segment, the catalytic loop with much of the catalytic machinery, the $\mathrm{p}+1$ loop and helix $\mathrm{F}$, are located. Connecting the two lobes are two hydrophobic spines, structures not connected in the primary sequence but hydrophobic clusters that introduce the possibility for dynamic regulation. The regulatory spine, which needs to be assembled in all active kinases, connects helix $\alpha \mathrm{C}$ to helix $\mathrm{F}$. The catalytic spine that is completed by the adenosine ring in ATP starts in the twisted $\beta$-sheet and is also anchored to the helix F [14]. A thorough review of how kinases are regulated is written by Taylor and Kornev [12].

\subsection{Receptors}

Receptors are proteins, which sense a signal, normally by binding a molecule called the ligand, and then mediating the signal over the cell membrane into the cell. The signal usually results in some kind of cell response for example glucose uptake.

\subsubsection{Eph Receptors and Ephrins}

The Eph receptors are the largest group of receptor tyrosine kinases (RTKs). The ligand to the Eph receptor is the ephrin, another protein bound to the membrane of another cell. The connection to the cell membrane makes the protein-protein interaction only possible when cells are in close proximity. The Eph receptor and the ephrins are involved in many complicated processes during development of new individuals and in the adult. The Eph/ephrin system is involved in for example formation of synaptic connections between neurons, blood vessel and bone remodeling, immune function and stem cell self-renewal $[15,16]$. The Eph receptors and the ephrins have been shown to be involved in various cancer forms [17] and in neurodegenerative diseases such as Alzheimer's disease [18]. The ephrins are divided into two groups, ephrin A's that are linked to the cell membrane by a glycophosphatidylinositol anchor and ephrin B's that have a transmembrane segment and a small cytosolic domain with a PDZ binding motif. The Eph receptors are also grouped into A or B receptors depending on whether they preferably bind to ephrinA's or ephrinB's. The Eph receptor consists of an ephrin binding domain, a cysteine rich region, two fibronection type III repeats, a single membrane spanning segment, a juxtamembrane segment (JMS), the catalytically active kinase domain (KD), a SAM domain and a PDZ binding motif (figure 1.4). When the Eph receptor binds the ephrin, the Eph receptor multimerizes; the intracellular domains gets autophosphorylated on 
multiple sites and the receptor is activated [19]. The Eph receptors differs from most RTKs by their way of not only sending signals into the receptor cell but also the other way around into the ephrin expressing cell. This is called bidirectional signaling.

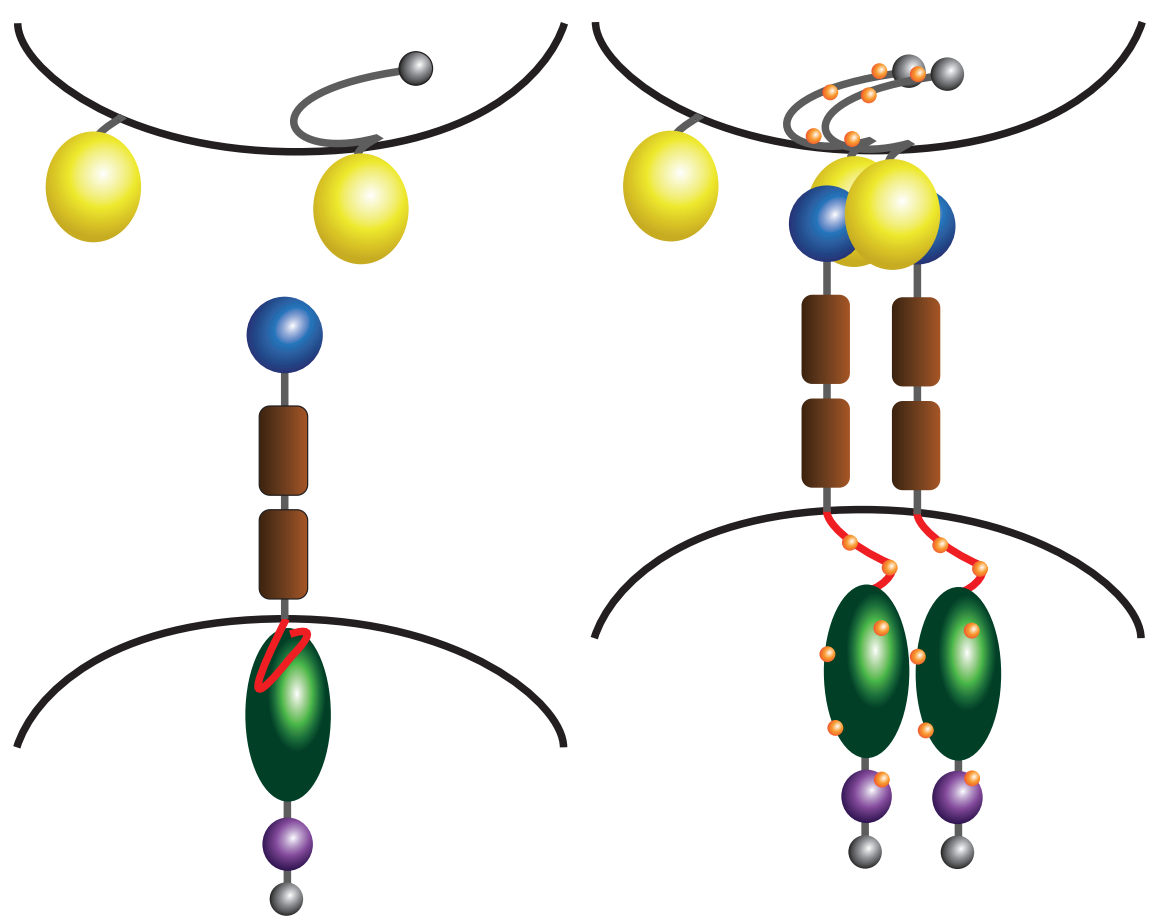

Figure 1.4: Schematic picture of the Eph receptor and the ephrins. Top left in the left panel is an ephrinA, top right is an ephrinB. The Eph receptor is positioned at the bottom. Blue is the ephrin binding domain, brown is two fibronection type III repeats, red is the juxtamembrane segment, green is the kinase domain, purple is a SAM domain and grey is a PDZ binding motif. Upon interaction between the Eph receptor and the ephrin the Eph receptor multimerizes, the intracellular domains get autophosphorylated on multiple sites and the receptor is activated. 
1. 


\section{Chapter 2}

\section{Studying Proteins}

The characteristics of a protein is dependent of numerous properties such as in what type of cells, when and to what extent it is present, which other proteins or molecules it interacts with, the structure of the protein, its dynamics, its stability and so on. There are almost as many techniques to study proteins with, as there are questions to ask about them. The foci of this thesis are protein structure, dynamics and interactions and the techniques described in this chapter are the ones used to investigate these properties.

\subsection{Structural Biology}

Structural biology is the scientific study of the three-dimensional structures of macromolecules. The structure is defined by the relative position of the different atoms of the macromolecule. The problem with single proteins is that they are so small that they will not be visible in a light microscope hence other tricks are needed to reveal their structure. Techniques such as cryo-electron microscopy and small angle X-ray scattering give lowresolution information. For high resolution structures there are two main techniques present, X-ray crystallography and nuclear magnetic resonance (NMR) spectroscopy.

\subsubsection{X-ray Crystallography}

$\mathrm{X}$-ray crystallography is based on the phenomenon of diffraction, where thousands of atoms, in proteins ordered into crystals, build up planes that make the X-ray beam divide in a well-defined diffraction pattern. The conditions for protein crystallization are often difficult to find and a lot of time is spent on the process of retrieving a good quality crystal. The 
first high-resolution structure was determined by X-ray crystallography [20] and it is still the most productive way to obtain high-resolution structures. There is no real upper limit for the size of the protein, but some proteins, such as membrane proteins and proteins with a lot of intrinsic flexibility, are complicated to crystallize although progress has been made [21]. For a more thorough introduction to X-ray crystallography, Crystallography made Crystal Clear by Gale Rhodes [22] is recommended.

\subsubsection{Nuclear Magnetic Resonance Spectroscopy}

NMR spectroscopy is based on the fact that some atomic nuclei have a property called nuclear spin. This property makes the nuclei act as tiny magnets. By inserting these tiny magnets in a large magnetic field, the NMR spectrometer, it is possible to get information about how they interact. This information can be transferred to atomic level information because in a protein, every nucleus generates a unique signal. One advantage of NMR spectroscopy is that the measurements can be performed in solution, making it a physiological structural biology method and enabling the study of protein dynamics. The measurement is also non-destructive and if the protein is stable at the temperature at which the measurements are performed the sample may be used and reused for years. The drawbacks of NMR spectroscopy is the low sensitivity, which results in long experimental times, the need for highly concentrated samples that may be complicated to produce and problems associated with conducting experiments on large proteins. NMR spectroscopy is the main technique of this thesis and will be further described in chapter 3 .

\subsection{Analytical Ultracentrifugation}

Analytical ultracentrifugation (AUC) is a method to determine molecular weight, as well as hydrodynamic and thermodynamic properties. The method is based on the fact that the size of a molecule determines how much it will be influenced by a gravitation force field. The field is produced by rotating the sample very quickly and by detecting where in the sample chamber the molecule is, it is possible to determine its size. In this thesis the method has been applied to determine how high concentration of different forms of the kinase domain of EphB2 is needed to make it bind to itself. All theory and equations in the following section derive from Introduction to Analytical Ultracentrifugation by Greg Ralston [23], unless otherwise noted.

There are three forces acting on a particle suspended in a solvent. The gravitational force, $F_{s}$, is proportional to the mass of the particle and the acceleration. In a spinning rotor the acceleration is determined by the dis- 
tance from the rotational origin, $r$, and the angular velocity, $\omega$, by

$$
F_{s}=m \omega^{2} r=\frac{M}{N} \omega^{2} r
$$

where $m$ is the mass, $M$ is the molecular mass and $N$ is the Avogadro constant. The second force is the buoyant force, $F_{b}$, equal to the displaced weight of the fluid according to

$$
F_{b}=-m_{0} \omega^{2} r=-m \bar{\nu} \rho \omega^{2} r=-\frac{M}{N} \bar{\nu} \rho \omega^{2} r
$$

where $\bar{\nu}$ is the partial specific volume, the volume that each gram of the solute occupies, and $\rho$ is the density of the solvent. If the density of the particle is larger than that of the solvent the particle will start to sediment. The velocity of the particle, $u$, will increase because the radial distance increases. The last force is the friction force, $F_{f}$, between the particle and the solution, related to the velocity by

$$
F_{f}=-f u
$$

where $f$ is the frictional coefficient that is dependent on the shape and size of the particle. Smooth, compact and spherical particles experience less friction than elongated bulky ones. Figure 2.1 summarizes the forces acting on the particle.

Normally within microseconds the forces are in balance and

$$
F_{s}+F_{b}+F_{f}=0 .
$$

By collecting the terms connected to particle size on one side and those terms connected to the experimental conditions on the other side the result

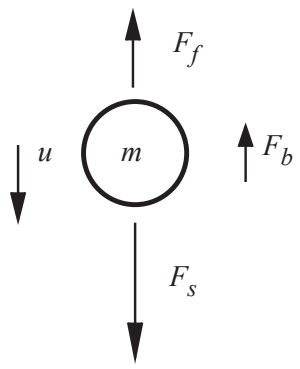

Figure 2.1: The forces acting on a particle with mass $m$ in a gravitational field: the frictional force, $F_{f}$, the buoyant force, $F_{b}$ and the gravitational force, $F_{s} . u$ is the constant speed of the rotation. (Adopted from [23].) 
is

$$
\frac{M(1-\bar{\nu} \rho)}{N f}=\frac{u}{\omega^{2} r} \equiv s
$$

where $s$ is called the sedimentation coefficient. When the process of sedimentation carries on the particles end up in the bottom of the sample chamber. The diffusion process starts to work in the opposite direction and after a sufficient time has elapsed the system is in sedimentation equilibrium (SE).

The AUC experiments in this thesis were performed at conditions of SE. The measured property was the absorbance, $a_{\lambda}$. Proteins at SE may be assumed to follow Boltzmann distribution, which gives the correlation

$$
a_{\lambda}(r)=c_{1,0} \varepsilon_{\lambda} d \exp \left[M_{1}(1-\bar{\nu} \rho) \frac{\omega^{2}\left(r^{2}-r_{0}^{2}\right)}{2 R T}\right]
$$

where $r$ is the distance from the rotational center, $c_{1,0}$ is the molar concentration a monomer, $\varepsilon_{\lambda}$ is the extinction coefficient for a monomer, $d$ is the path length of the sample cell, $M_{1}$ is the molecular weight of the monomer, $r_{0}$ is the distance from the rotational center to the start of the sample cell, $R$ is the molar gas constant and $T$ the absolute solute temperature [24]. SE experiments are performed at different velocities and all velocities are fitted simultaneously to find the molecular mass that best fits the data. If the molecular mass is much higher than expected it is reasonable to assume that oligomerization is taking place. The molecular weight is then held constant and the data is instead fitted to the following equation

$$
\begin{aligned}
a_{\lambda}(r)=c_{1,0} \varepsilon_{\lambda} d \exp & {\left[M_{1}(1-\bar{\nu} \rho) \frac{\omega^{2}\left(r^{2}-r_{0}^{2}\right)}{2 R T}\right] } \\
+ & 2 \varepsilon_{\lambda} d K_{12}\left(c_{1,0}\right)^{2} \exp \left[2 M_{1}(1-\bar{\nu} \rho) \frac{\omega^{2}\left(r^{2}-r_{0}^{2}\right)}{2 R T}\right]
\end{aligned}
$$

where $K_{12}$ is the equilibrium constant between monomer and dimer [24]. In the case of the kinase domain of EphB2 (described in Paper V) the monomer-dimer model was not sufficient to explain all of our data and a monomer-dimer-tetramer model was used represented by the following equation

$$
\begin{aligned}
& a_{\lambda}(r)=c_{1,0} \varepsilon_{\lambda} d \exp {\left[M_{1}(1-\bar{\nu} \rho) \frac{\omega^{2}\left(r^{2}-r_{0}^{2}\right)}{2 R T}\right] } \\
&+2 \varepsilon_{\lambda} d K_{12}\left(c_{1,0}\right)^{2} \exp \left[2 M_{1}(1-\bar{\nu} \rho) \frac{\omega^{2}\left(r^{2}-r_{0}^{2}\right)}{2 R T}\right] \\
&+4 \varepsilon_{\lambda} d K_{14}\left(c_{1,0}\right)^{4} \exp \left[4 M_{1}(1-\bar{\nu} \rho) \frac{\omega^{2}\left(r^{2}-r_{0}^{2}\right)}{2 R T}\right]
\end{aligned}
$$

where $K_{14}$ is the equilibrium constant between monomer and tetramer [24]. 


\section{Chapter 3}

\section{Nuclear Magnetic Resonance Spectroscopy}

There are two main subdivisions of NMR spectroscopy, solution state and solid state. Solid state NMR is performed in media with low mobility. This experimental setup benefits membrane proteins and protein aggregates not suitable for solution state NMR. However, the reduced mobility also reduces the possibility to study properties such as protein dynamics, which instead is an excellent subject for solution state NMR. This thesis will henceforward only cover solution state NMR spectroscopy, referred to as NMR spectroscopy and the main focus is its application to proteins. The theory behind NMR is described in many textbooks, for example Spin Dynamics by Malcolm Levitt [25], Nuclear Magnetic Resonance and Relaxation by Brian Cowan [26] and Protein NMR Spectroscopy by John Cavanagh et al. [27] that are the main sources for this chapter.

\subsection{Fundamentals of NMR Spectroscopy}

As already mentioned, the phenomenon NMR is built upon is the nuclear spin and its magnetic moment. The spin is quantized and the nuclear spin quantum number is conventionally denoted $I$. Not all nuclei have a spin quantum number separate from zero but the, for protein NMR important, isotopes ${ }^{1} \mathrm{H},{ }^{13} \mathrm{C}$ and ${ }^{15} \mathrm{~N}$ all have $I=1 / 2$. A nuclear state with spin $I$ is $(2 I+1)$-fold degenerated, specified by the quantum number $m$. A magnetic field breaks this degeneracy and results in a Zeeman nuclear splitting. The energy steps between these levels correspond to the energy of radio frequency (r.f.) waves and NMR spectroscopy manipulates the spins by r.f. pulses and detects the spins changing between the different nuclear Zeeman sub levels. 
The selection rule for detecting the NMR signal is that $\Delta m$ is \pm 1 .

\subsubsection{Larmor Frequency}

The magnetic moment, $\hat{\mu}$, is proportional to the spin angular momentum, $\hat{S}$, that indicates the axis of rotational motion related as

$$
\hat{\mu}=\gamma \hat{S}
$$

where $\gamma$ is the gyromagnetic ratio, specific for every isotope, and the 'hat' indicates quantum mechanical operators. Because of the spin angular momentum, spins placed in an external magnetic field will precess around the external field, with constant angle and frequency, $\omega_{0}$, also called the Larmor frequency given by

$$
\omega_{0}=-\gamma B_{0}
$$

where $B^{0}$ is the magnetic field. In absence of an external magnetic field, the distribution of the spin angular momenta is totally isotropic, but in the external magnetic field the energy of the spins will be different depending on the orientation. Because of tiny fluctuations in the local magnetic field, experienced by each spin, the spin angular momenta are constantly changing direction and will sample all possible orientations with a slight tendency to sample a less energetic orientation. This results in a somewhat anisotropic distribution where the system is stable but not static at a state called the thermal equilibrium with a resulting macroscopic magnetic moment, possible to manipulate by r.f. pulses.

\subsubsection{Chemical Shifts}

The external magnetic field that the NMR sample experiences is designed to be as uniform as possible. However, even if the spectrometer magnet is perfect the sample itself will interact with the magnetic field and slightly alter the local magnetic fields that the different nuclei experience. This results in different Larmor frequencies, called chemical shifts, for different nuclei of the same species. The chemical shifts contain valuable information that help distinguishing between different chemical groups such as the ${ }^{13} \mathrm{C}$ in a carbonyl group and that of the $\mathrm{C} \alpha$ position, but also between $\mathrm{C} \alpha$ 's in different residue types such as glycine and serine as well as indicating the secondary structure of that residue [28]. Recently it has been discovered that it is possible to determine the structure of a protein with the chemical shifts as the sole constraints [29,30].

The chemical shifts originate from the external magnetic field influencing the electrons surrounding the nuclei to circulate, which consequently induces 
a magnetic field. The local field, $B_{\text {loc }}^{j}$, that the nucleus $j$ experiences is the sum of the external field, $B^{0}$, and the induced field, $B_{\text {ind }}^{j}$.

$$
B_{\mathrm{loc}}^{j}=B_{0}+B_{\text {ind }}^{j}
$$

The chemical shift is well correlated with electronegativity of adjacent atoms. Neighboring three-dimensional structures such as benzene rings will influence the local fields depending of the orientation and proximity of the ring relative to the nucleus.

The chemical shift is related to the specific Larmor frequency as

$$
\delta=\frac{\omega-\omega_{\text {ref }}}{\omega_{\text {ref }}} \times 10^{6} \mathrm{ppm}
$$

where $\omega$ is the Larmor frequency of the particular nucleus and $\omega_{\text {ref }}$ is the Larmor frequency of the same isotope in the reference compound. In protein NMR experiments the methyl ${ }^{1} \mathrm{H}$ in 2,2-dimethyl-2-silapentane-5-sulfonic acid (DSS) is used as reference for the proton. DSS may be added to the sample but often referencing is performed by measuring the frequency of water and then the theoretical chemical shift of water is calculated relative to DSS at the current temperature. Multiplying isotope specific constants to the frequency of the proton then references other isotopes.

\subsubsection{NMR Experiments}

NMR experiments build on manipulation of the net magnetic moment and subsequent detection of the voltage the magnetic moments induce in the probe. The simplest NMR experiment consists of; the preparation step,

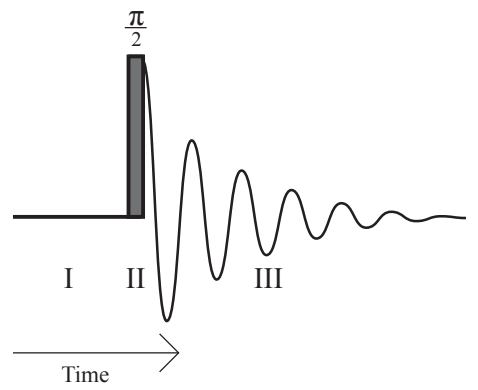

Figure 3.1: A representation of a simple pulse sequence with $\mathrm{I}$, time for thermal equilibrium to be recovered, II, one $\frac{\pi}{2}$-pulse that disturbs the thermal equilibrium and III, the acquisition of the FID. 


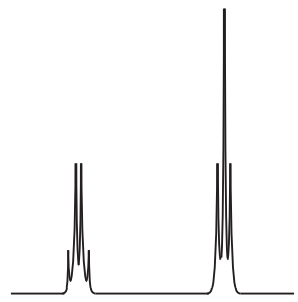

Figure 3.2: The simulated ${ }^{1} \mathrm{H}$ spectrum of ethanol (adopted from [25]). The splitting of the signal originates from the scalar coupling described in 3.1.4.

a single pulse disturbing the equilibrium and acquisition, detection of the signal. The acquired signal is called the FID (free induction decay), a decaying signal labeled with all the frequencies of the spins present in the sample. The properties of an experiment are defined in a pulse sequence. Figure 3.1 shows a representation of a simple pulse sequence. By altering the number and properties of the pulses and the delays in-between the experiment is modified. To increase sensitivity, the pulse sequence is usually repeated multiple times because the NMR signal to noise ratio scales with $\sqrt{n}$, for $n$ repetitions of the pulse sequence. Another reason to repeat the pulse sequence is that by changing the phases of certain pulses in-between the repetitions, called phase cycling, artifacts originating from imperfections in the spectrometer, may be reduced.

\section{The NMR Spectrum}

For simpler interpretation, the FID is converted from the time dimension to the frequency dimension normally by Fourier transformation. The data is referenced using the chemical shift method described in equation 3.4 and the result is a spectrum where all frequencies prominently present in the FID ends up as peaks. In figure 3.2 a one-dimensional spectrum of ethanol is shown. For proteins, the resolution of the one-dimensional spectrum is generally to low to draw any advanced conclusions. An example of a onedimensional spectrum of the kinase domain of EphB2 is shown in figure 3.3 .

\subsubsection{Spin Interactions}

Spin interactions are direct or indirect couplings between spins that cause for example; the splitting of the peaks seen in figure 3.2, the possibility to transfer magnetization between nuclei and relaxation (further described 
3.

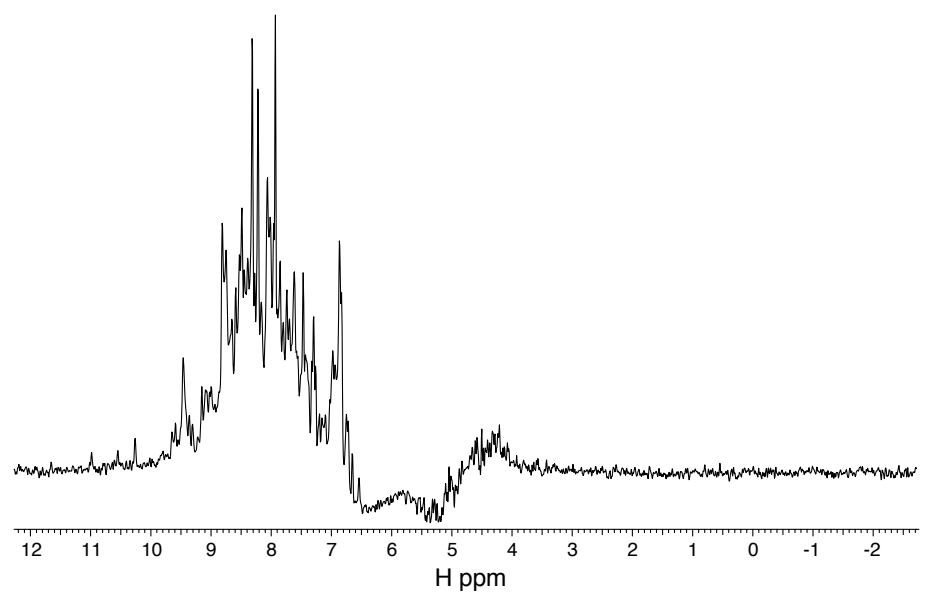

Figure 3.3: ${ }^{1} \mathrm{H}$ spectrum of the amide region of the kinase domain of EphB2.

in 3.2). There are five different types of spin interactions that may cause relaxation $(c f$.$) :$

1. direct dipole-dipole interaction

2. scalar couplings

3. chemical shift anisotropy

4. quadrupolar interactions

5. spin-rotation interaction

of which the first three are important for spin $I=1 / 2$ nuclei in isotropic liquids. In anisotropic liquids the orientations of the molecules are not equally probable and that will influence some of the interactions.

\section{Direct Dipole-Dipole Interaction}

Each precessing nucleus is a magnetic dipole not only responding to external magnetic fields but it is itself the source of a field. Direct dipole-dipole interactions are, as the name implies, direct interactions between these dipoles mediated through space. If vibrational motions are ignored the dipole-dipole coupling constant is

$$
b=-\frac{\mu_{0}}{4 \pi} \frac{\hbar \gamma_{1} \gamma_{2}}{r^{3}}
$$


where $\mu_{0}$ is the permeability constant, $\hbar$ the reduced Planck constant, $\gamma_{1}$ and $\gamma_{2}$ the gyromagnetic ratio of the two interacting spins and $r$ the distance between the spins. In isotropic liquids the dipole-dipole couplings are not the origin of any signal splitting. The probability of a transition that will result in relaxation is proportional to the square of the dipoledipole coupling and therefore the inverse sixth of the distance between the spins, which is used in the nuclear Overhauser enhancement spectroscopy (NOESY) experiment. This can be used for structure calculations.

\section{Scalar Couplings}

Scalar couplings are also called indirect dipole-dipole, spin-spin or J-couplings. An ${ }^{1} \mathrm{H}$ nucleus, bound to a ${ }^{13} \mathrm{C}$ nucleus, will magnetize the electrons in the bond, generating a field that the ${ }^{13} \mathrm{C}$ spin will experience and at the same time the ${ }^{13} \mathrm{C}$ spin will influence the ${ }^{1} \mathrm{H}$ spin. For qualitative molecular structural information, the J-coupling is very important, however in protein NMR spectroscopy the splitting of the signal intensity into multiple, low intensity, less discernable peaks, results in data that is difficult to interpret. The scalar coupling may however be eliminated by continuously applying, radio frequency pulses corresponding to the Larmor frequency of the ${ }^{13} \mathrm{C}$ spin and the ${ }^{1} \mathrm{H}$ spin will behave as if the scalar coupling does not exist. This is called heteronuclear decoupling. In protein NMR spectroscopy the scalar coupling is mostly utilized for transferring magnetization between nuclei, which allows multidimensional experiments to be conducted (described in 3.1.5).

\section{Chemical Shift Anisotropy}

Chemical shifts, described in 3.1.2 are more complicated than just a constant and are more accurately described by the chemical shift tensor, $\delta^{j}$. The induced field for nucleus $j$ may be approximated to a linear dependency of the external field by

$$
B_{\text {ind }}^{j}=\delta^{j} B_{0} .
$$

The chemical shift anisotropy (CSA) originates from the fact that $\delta^{j}$ almost always is anisotropic. The chemical shift anisotropy, $\delta_{\text {aniso }}^{j}$, is the largest deviation of the chemical shift tensor from the isotropic value, $\delta_{\text {iso }}^{j}$

$$
\delta_{\text {aniso }}^{j}=\delta_{Z Z}^{j}-\delta_{\text {iso }}^{j}
$$

where the $Z Z$ axis is assigned to the axis of the chemical shift tensor that gives the largest value of $\delta_{\text {aniso }}^{j}$. The consequence of the anisotropic chemical shift is that the local magnetic field will change orientation as the molecule rotates in solution, which does not result in signal splitting in liquids, because of the fast rotation, but is a source of relaxation. Relaxation by CSA 
is most important for nuclei with large chemical shift ranges and the CSA relaxation constant has a quadratic relationship to the external magnetic field. This gives noticeable effect for example for the carbonyl carbon, for which it is not always efficient to conduct experiments at higher fields to increase sensitivity.

\section{Quadrupolar Interactions}

Quadrupolar interactions are the electrical interactions of spin $I>1 / 2$ with the electrical field generated by the electrons surrounding the nuclei. These nuclei have a charge distribution that is asymmetric and therefore the electric field it induces changes when the nuclei rotate. The quadrupolar moment describes how far from spherical symmetry the nuclear charge distribution is. The spins most important for this thesis have spin $I=1 / 2$ for which there is no quadrupolar moment and hence no quadrupolar coupling. However, for nuclei with spins $I>1 / 2$, for example ${ }^{2} \mathrm{H}$, the quadrupolar relaxation mechanism is the overall dominant source of relaxation.

\section{Spin-Rotation Interaction}

Spin-rotation interactions are interactions of magnetic fields, generated by the rotating molecule, with the nuclear spins. The interaction is only marginally important in solution state NMR but has major effect on relaxation in the gas phase.

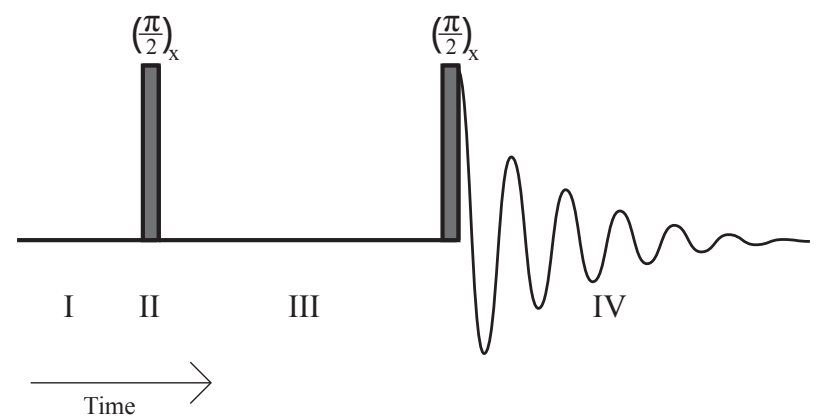

Figure 3.4: The first two-dimensional NMR experiment described, the COSY pulse sequence. I, time for thermal equilibrium to be recovered, II, one $\pi / 2$ pulse that disturbs the thermal equilibrium, III, the $t_{1}$ evolution period as well as the transfer period, IV, the acquisition of the FID. 


\subsubsection{Multidimensional Experiments}

To resolve the NMR signals, for complex molecules such as proteins, and to establish connections between signals, multidimensional experiments are used. These involve time intervals, called mixing periods, where magnetization is transferred between nuclei, and intervals, called evolution periods, where the signal is labeled with the frequencies of the different nuclei. The experiment ends with the evolution period of the direct dimension. If the signal is labeled with two chemical shifts the transformed spectrum will result in a two-dimensional spectrum. To be able to label the signal with different chemical shifts in the indirect dimension, the pulse sequence is repeated multiple times with increasing length of the indirect evolution period. The pulse sequence for the first two-dimensional experiment described, the COSY experiment, is shown in figure 3.4 [31]. The COSY experiment correlates coupled protons, in proteins separated by two or three bonds.

\subsubsection{Heteronuclear Experiments}

In heteronuclear experiments, the individual nuclei the magnetization is transferred between are of different kinds. One of the most common protein experiments is the heteronuclear single-quantum coherence (HSQC) experiment or the transverse relaxation optimized spectroscopy (TROSY) variant

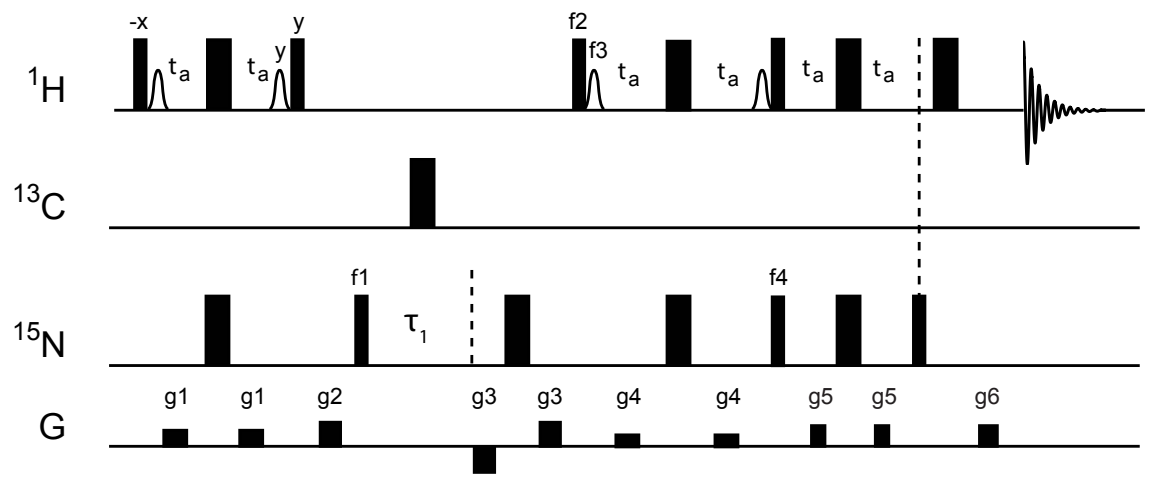

Figure 3.5: An example of a TROSY based HSQC example that has been used on the kinase domain of EphB2. Four different channels, ${ }^{1} \mathrm{H}$, ${ }^{13} \mathrm{C},{ }^{15} \mathrm{~N}$ and the gradient channels are shown. Narrow bars indicate hard $\pi / 2$-pulses, broad bars hard $\pi$-pulses and shaped bars are shaped pulses. The phase of the pulse is $\mathrm{x}$ if nothing else is indicated. $\mathrm{fx}$ indicates that the pulse is phase cycled. $\tau_{1}$ is the evolution period on ${ }^{15} \mathrm{~N}$ and $\mathrm{t}_{\mathrm{a}}$ is $1 / 4 J_{H N}$. 
(described in 3.4.1), where the NMR signal is labeled with the chemical shifts of two covalently linked nuclei. This is normally used as a fingerprint of the protein to check that the state of the protein is satisfactory. Higher dimensional experiments and relaxation experiments are often built on the HSQC experiment. One TROSY pulse sequence is shown in figure 3.5. The experiment has been conducted on the kinase domain of EphB2 and when transformed the spectrum looks like in figure 3.6. Because this is a two-dimensional spectrum the intensities of the peaks are indicated with altitude lines. In comparison with figure 3.3 the individual peaks are much more easily distinguished in this spectrum. Heteronuclear experiments generally starts and ends with the magnetization on the proton because the gain in sensitivity when ${ }^{1} \mathrm{H}$ is used compared with ${ }^{13} \mathrm{C}$ or ${ }^{15} \mathrm{~N}$ is $n\left(\gamma_{H} / \gamma_{S}\right)^{5 / 2}$, where $n$ is the number of hydrogens on the nitrogen or carbon and $\gamma_{H}$ and $\gamma_{S}$ is the gyromagnetic ratio for proton and ${ }^{13} \mathrm{C}$ or ${ }^{15} \mathrm{~N}$, respectively. However for solvent exposed parts of the protein the exchange rate of hydrogens may be so fast that they are exchanged during the experiment, leading to loss of signal in affected areas. In Paper $\mathrm{V}$, this was a problem that could have been avoided with pulse sequences eluding magnetization on protons.

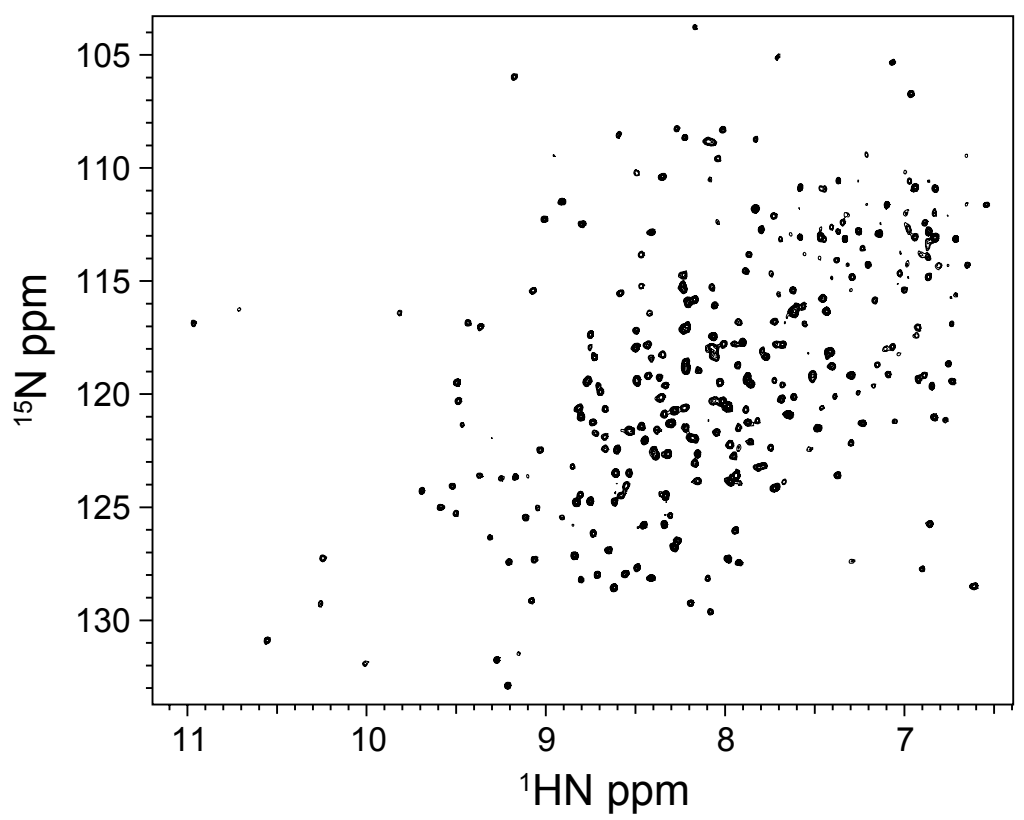

Figure 3.6: The two-dimensional spectrum of the kinase domain of EphB2 from the experiment shown in figure 3.5. 
For optimal sensitivity in these experiments the spectrometer needs to be optimized for detection at carbon or nitrogen.

\subsubsection{Resonance Assignments}

Every peak in a heteronuclear spectrum corresponds to one set of correlated nuclei and without knowing which peak belongs to which nuclei the experiments are very hard to interpret. The process of pairing the peaks to the different nuclei is called assignment and may be a time consuming and sometime impossible task. The main idea behind the assignment process is to perform experiments where the NMR signal is labeled with the properties of a few linked nuclei into a spin system. Because the residues in a protein are covalently linked it is possible to transfer magnetization to the same nuclei starting from two adjacent residues. This results in two spin systems sharing the same chemical shifts for one or more nuclei, making it possible to link spin systems to each other. Some residues have distinctive chemical shifts, such as glycine, alanine, serine and threonine, which help when positioning the linked residues in the protein sequence. When a protein consists of a few hundred amino acids, the assignment process is however not straightforward and the task is similar to solving a large jigsaw puzzle where probably not all pieces are present and many fit in multiple places. Numerous computer programs have been developed to facilitate the assignment process [32-35] and the software COMPASS in Paper I is one additional example.

\subsubsection{Isotopic Labeling}

For NMR spectroscopists the most interesting backbone atoms of the protein are nitrogens, carbons and hydrogens but the majority of the carbon and nitrogen isotopes are the non-magnetically active isotope ${ }^{12} \mathrm{C}$ and the spin $I=1$ isotope ${ }^{14} \mathrm{~N}$. To be able to run heteronuclear experiments, where magnetization is transferred from proton, to nitrogen, to carbon, the spin $I=1 / 2$ nuclei ${ }^{15} \mathrm{~N}$ and/or ${ }^{13} \mathrm{C}$ need to be incorporated into the protein. This is done by growing the protein-expressing bacteria in a medium supplemented with only one nitrogen source containing ${ }^{15} \mathrm{~N}$ and one carbon source containing ${ }^{13} \mathrm{C}$. Normally ${ }^{15} \mathrm{~N}$-ammonium chloride and ${ }^{13} \mathrm{C}$-glucose are used for a uniformly labeled protein. For certain methods, such as certain relaxation experiments specific carbons need to be labeled selectively and this is described in 3.3 . 


\subsection{Relaxation}

Relaxation is the process when the system reestablishes the thermal equilibrium that has been disturbed by the r.f. pulses in the NMR experiment. The spontaneous relaxation process of an isolated spin is very improbable and is instead a consequence of the interactions, described in 3.1.4, between the spin and the surroundings. There are in principle two types of relaxation; longitudinal relaxation where the spins relax back to the Boltzmann distribution, giving the net magnetization at thermal equilibrium, and by transverse relaxation, which is the loss of coherence detectable in the FID. Relaxation is sensitive to processes on different time scales, which are taken advantage of to study interactions, otherwise hidden in an ordinary NMR spectrum, and different protein motions.

\section{Relaxation Mechanisms and Spin Quantum Number}

In solution NMR spectroscopy the fluctuating magnetic fields, caused by thermal motions of the molecule, are the main source of relaxation for spin $I=1 / 2$ and the importance of the different relaxation mechanisms is usually as follows:

$$
\text { dipole-dipole }>\text { CSA }
$$

The CSA becomes more important at higher external magnetic fields, especially for nuclei such as the carbonyl carbon. For spin $I>1 / 2$ the importance is as follows:

$$
\text { quadrupole } \gg \text { dipole-dipole }>\text { CSA }
$$

When many relaxation mechanisms occur there is always the possibility of cross-correlation or relaxation interference between the different mechanisms. The many local fluctuating magnetic fields all depend on the rotation of the molecule and are therefore correlated. Relaxation interference forms the basis of TROSY described in 3.4.1.

\section{Longitudinal Relaxation}

Longitudinal relaxation is the process where the spins in the sample relax back to the thermal equilibrium by losing their energy to the surroundings, which influences the magnitude of magnetization along the longitudinal axis, hence the name. Longitudinal relaxation is schematically illustrated in figure 3.7. The process that dominates this relaxation for protons is the dipoledipole interaction. The time constant that describes the time it takes for the spins to relax back to equilibrium is called $T_{1}$ and the relaxation process at a constant external magnetic field is described by

$$
M_{z}(t)=M_{0}-\left[M_{0}-M_{z}(0)\right] \exp \left(-t / T_{1}\right)
$$




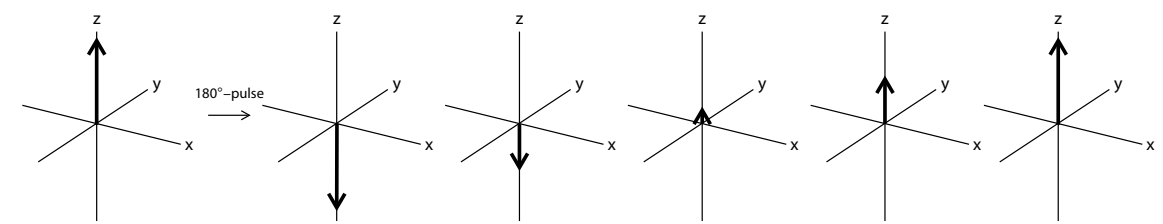

Figure 3.7: Schematic illustration of the longitudinal relaxation process. The net magnetization (arrow) is inverted between the two first pictures and is then relaxing back as time passes.

where $M_{0}$ is the equilibrium value of $M_{z}$ and $t$ is the time. For proteins this time is typically in the range of seconds and $T_{1}$ passes a minimum and then increases with increasing molecular size. $T_{1}$ determines how often the pulse sequence may be repeated in the experiment. For maximum sensitivity the time between the repetitions of the pulse sequence needs to be optimized so enough signal has relaxed back between scans and a high number of repetitions can be performed.

\section{Transverse Relaxation}

Transverse relaxation is the irreversible loss of coherence, which can be seen as loss of the detectable net magnetization due to the spreading out of the magnetization in the transverse plane, perpendicular to the longitudinal axis, schematically illustrated in figure 3.8. The main source of the transverse relaxation is the difference in magnetic environment that the different spins experience, which will make them precess with slightly different rates and the spins that were collective in the beginning are now spread out in the transverse plane. $T_{2}$ is the constant describing the time it takes for the coherence to vanish or the spins to completely spread out in the transverse

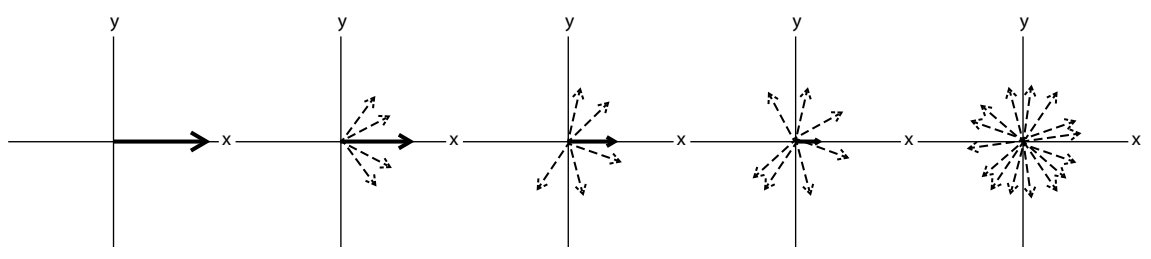

Figure 3.8: Schematic illustration of the transverse relaxation process. The net magnetization (bold arrow) relaxes by loss of coherence, resulting in zero magnetization in the transverse plane. The spins that are in phase in the left panel gets more and more scattered after time. 
plane so the net magnetic vector in the plane is zero and is described by

$$
M_{x}(t)=M_{x}(0) \cos \left(\omega_{0} t\right) \exp \left(-t / T_{2}\right)
$$

where $M_{x}$ is the magnetization along the x-axis, $\omega_{0}$ is the Larmor frequency and $t$ is the time. $T_{2}$ determines for how long time it is possible to detect the FID. $T_{2}$ also influences the shape of the peaks in the spectrum. Shorter transverse relaxation time results in broader peaks that eventually will be so wide that they disappear in the noise and will be undetectable.

\subsubsection{Pico-Nanosecond Time Frame Experiments}

Motions on the pico-nanosecond timeframe are small motions where the atomic bonds are bending, stretching and rotating. These are normally studied with experiments determining the longitudinal relaxation rate constants, $R_{1}$, the transverse relaxation rate constants, $R_{2}$, and the heteronuclear NOE (nuclear Overhauser effect) [36]. These parameters may be individually determined for each nucleus and therefore they are well suited to report on flexibility with atomic resolution. If all three experiments are collected it is possible to calculate the order parameter, $S^{2}$, that describes if a nucleus is moving like the rest of the protein $S^{2}=1$, totally unrelated to the rest of the protein $S^{2}=0$ or somewhere in-between. The calculation of $S^{2}$ is usually done with the model-free formalism $[37,38]$ or the extended model-free formalism [39], which optimally requires some additional experiments.

\section{$\boldsymbol{R}_{1}$}

The longitudinal relaxation rate constant $R_{1}$ is the inverse of $T_{1}$ and may be measured by the $T_{1}$ relaxation experiment which is built on the idea to invert the equilibrium magnetization, wait a variable delay time and then transfer the magnetization to the transverse plane and detect how much of the initial magnetization was left along the longitudinal axis after the delay. The experiment is repeated with different delays and the intensity of the magnetization is fitted to equation 3.8 to extract $T_{1}$ [40]. The most well studied nucleus in proteins is the amide ${ }^{15} \mathrm{~N}$ due to convenience and sensitivity.

\footnotetext{
$\boldsymbol{R}_{2}$

$R_{2}$, the transverse relaxation rate constant, is the inverse of $T_{2}$. There are experiments that directly detect $R_{2}$ but it is common to instead use the more robust $R_{1 \rho}$ experiment. If $R_{1}$ is known it is possible to calculate $R_{2}$
} 
according to

$$
R_{2}=\frac{R_{1 \rho}}{\sin ^{2} \theta}-\frac{R_{1}}{\tan ^{2} \theta}
$$

where $\theta$ is the tilt-angle, defined as

$$
\theta=\frac{B_{1}}{\Delta \Omega}
$$

where $B_{1}$ and $\Delta \Omega$ are the spin lock field strength and the offset from the carrier, respectively [41]. For rigid molecules $R_{2}$ is highly dependent on the overall tumbling of the molecule, which means that in areas with high order parameters, $R_{2}$ is proportional to the size of the molecule in solution. This is used in Paper $\mathrm{V}$ to study self-association of the kinase domain of EphB2 to multimers.

\section{The heteronuclear $N O E$}

The heteronuclear $N O E$ reports on the motion of a bond vector, normally the ${ }^{15} \mathrm{~N}-{ }^{1} \mathrm{HN}$ bond, and is sensitive to $S^{2}$. The experiment to determine the heteronuclear $N O E$ is performed by two almost identical pulse schemes, where the coupled nucleus is saturated or not. Saturation may be performed by irradiating one spin with closely spaced $120^{\circ}$-pulses, which also affects a coupled spin by the direct dipole-dipole interaction. The heteronuclear NOE, for one nucleus, is calculated as the ratio between the intensities of the resulting peaks, with, $I_{\text {sat }}$, and without, $I_{\text {unsat }}$, saturation of the coupled nucleus [40].

$$
N O E=\frac{I_{\text {sat }}}{I_{\text {unsat }}}
$$

\subsubsection{Relaxation and Chemical Exchange}

As introduced in 1.2.3 one important process that influences the shape of the peaks in the NMR spectrum is chemical exchange. In the case of a two-state exchange process, the protein is changing between two different states, $a$ and $b$, with distinctive precession frequencies, $\omega_{a}$ and $\omega_{b}$. The NMR peaks will be influenced differently by the exchange, depending on the relationship between the difference between the two frequencies, $\Delta \omega$, of the peaks in the two states

$$
\Delta \omega=\omega_{a}-\omega_{b}
$$

and by the exchange rate constant, $k_{e x}$. If these parameters have roughly the same magnitude, the system is in the intermediate exchange regime

$$
k_{e x} \approx\left|\frac{\Delta \omega}{2}\right|
$$


If the relationship instead is

$$
k_{e x} \ll\left|\frac{\Delta \omega}{2}\right|
$$

the regime is called the slow exchange regime. The fast exchange regime is true for the relationship

$$
k_{e x} \gg\left|\frac{\Delta \omega}{2}\right| \text {. }
$$

In the slow exchange regime, the two states show two separate peaks in the spectrum with frequencies $\omega_{a}$ and $\omega_{b}$, see figure 3.9. In the fast exchange regime only one peak is visible in the spectrum at the frequency in-between $\omega_{a}$ and $\omega_{b}$ (figure 3.9, bottom). The intermediate exchange regime is characterized by one broad peak (middle panel, figure 3.9). In-between these regimes, the peaks are a mixture of the different regimes. If the two states are not equally populated the volumes of the peaks will be weighted with the relative populations in the slow intermediate exchange regime and the peak from the low populated state will be broader than that from the highly populated state due to a higher rate constant out of the corresponding state. The position of the single peak will be weighted towards the highest populated state in the fast exchanging regime. Because the exchange regime is dependent of the frequency difference the appearance of the peaks may change by altering the external field. The exchange rate constant is usually temperature dependent so changing the temperature may also change the exchange regime.

\section{Low Populated Excited States}

In proteins there may be low populated excited states not directly detectable in the NMR spectrum, as the above-mentioned peaks, but of significant biological relevance nevertheless. Especially interesting is the millisecond to microsecond time frame because of important processes such as protein folding [2], misfolding [42], catalysis [3,4] and ligand binding [5] that occur on this timescale. These states may be investigated by different methods depending of the time frame of the exchange rate constant. Chemical exchange saturation transfer (CEST) is a recently developed technique for determination of slow millisecond dynamics (5-50 ms) [43]. The experiment is performed by applying a weak r.f. pulse at different regions of the spectrum and when the frequency of the excited state is irradiated, the ground state will also be influenced. The experiment bank has been expanded to cover the backbone ${ }^{15} \mathrm{~N}[43,44],{ }^{13} \mathrm{C}$ [45-47], ${ }^{1} \mathrm{H}$ [48] and the side chains [49] and may be performed on uniformly labeled proteins. For fast exchange processes, 25-500 $\mu \mathrm{s}$, the $R_{1 \rho}$ dispersion experiment [50] is the best choice. This experiment is based on the same principle as the experiment described 


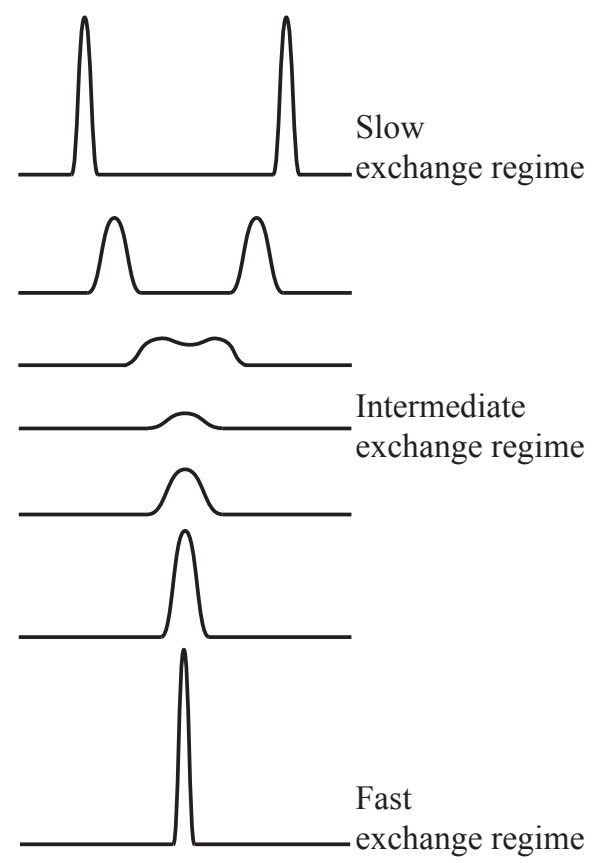

Figure 3.9: Schematic peak appearance of a two state exchange process, of equal populations, in different exchange regimes starting from slow at the top to fast at the bottom. The total volume of each peak or set of peaks should be the same even though this might not be obvious from the figure.

in 3.2.1 but in the dispersion version of the experiment the spin-lock r.f. frequency is changed between repetitions, which enables extraction of information about the excited state. Also here, multiple pulse sequences have been developed for different nuclei [50-53].

\section{CPMG Relaxation Dispersion}

Carr-Purcell-Meiboom-Gill (CPMG) relaxation dispersion is a type of NMR experiments designed to detect dynamics on the $0.5-5 \mathrm{~ms}$ time scale [5456]. A protein undergoing chemical exchange, to a low populated state, experiences different relaxation in the two states and will therefore show a relaxation rate $R_{2, \text { eff }}$ that is a sum of the relaxation rates in the ground state,

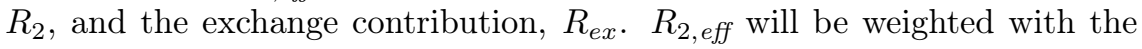
time the protein spends in the different states, the exchange rate constant, $k_{e x}$, how much of the protein is in the excited state, $p_{b}$, and the absolute 


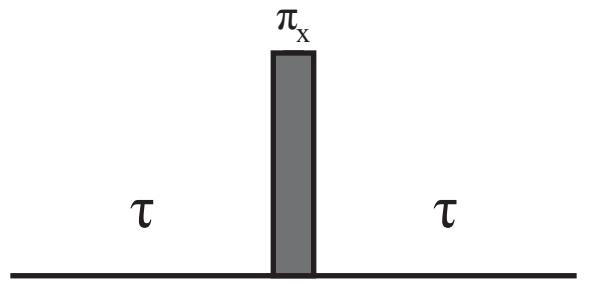

Figure 3.10: The pulse scheme of a spin echo, designed to refocus the magnetization of spins with different chemical shifts.

frequency difference, $|\Delta \omega|$, according to

$$
R_{e x}=\frac{p_{a} p_{b} \Delta \omega^{2}}{k_{e x}}
$$

To obtain the sign of $|\Delta \omega|$ two-dimensional correlation maps, recorded at numerous static magnetic fields are used [57].

The CPMG experiment may detect small populations, $0.5 \%$ and higher. $k_{e x}$ and $p_{b}$ describes the thermodynamics of the exchange and have been longtime recognized for their usefulness. $|\Delta \omega|$ has recently been promoted in importance because the chemical shifts are sufficient for structural calculations of protein excited states $[29,30]$.

The theory behind the CPMG experiment is that spins precessing in the transverse plane will be spread out due to chemical shift. A simple spin echo, shown in figure 3.10, may refocus these. If the spins are in chemical exchange during the spin echo, it will not be able to refocus the spins because the spins do not precess with the same frequency in the two states. In the CPMG experiment different rates of spin echoes, $\nu_{C P M G}$ will be applied during the same time interval $[58,59]$. If the system undergoes exchange; a high number of refocusing pulses will be able to refocus the spins better, resulting in lower effective relaxation than with a low number of repeats. A non-exchanging system will have the same effective relaxation rate independent of $\nu_{C P M G}$. The principle behind the CPMG relaxation dispersion experiment is illustrated in figure 3.11.

In this thesis, the software CATIA (http://pound.med.utoronto.ca/ flemming/catia/) has been used to extract the exchange parameters from the dispersion curves. The software uses the Bloch-McConnell equations to describe the evolution matrix of the spin-system in the case of chemical exchange and the exchange parameters are fitted by a least-square minimization. The exchange regime limits for the CPMG relaxation dispersion experiments are determined by the rate of the pulses possible to apply. If the exchange process is much slower than the relaxation delay, it is not 

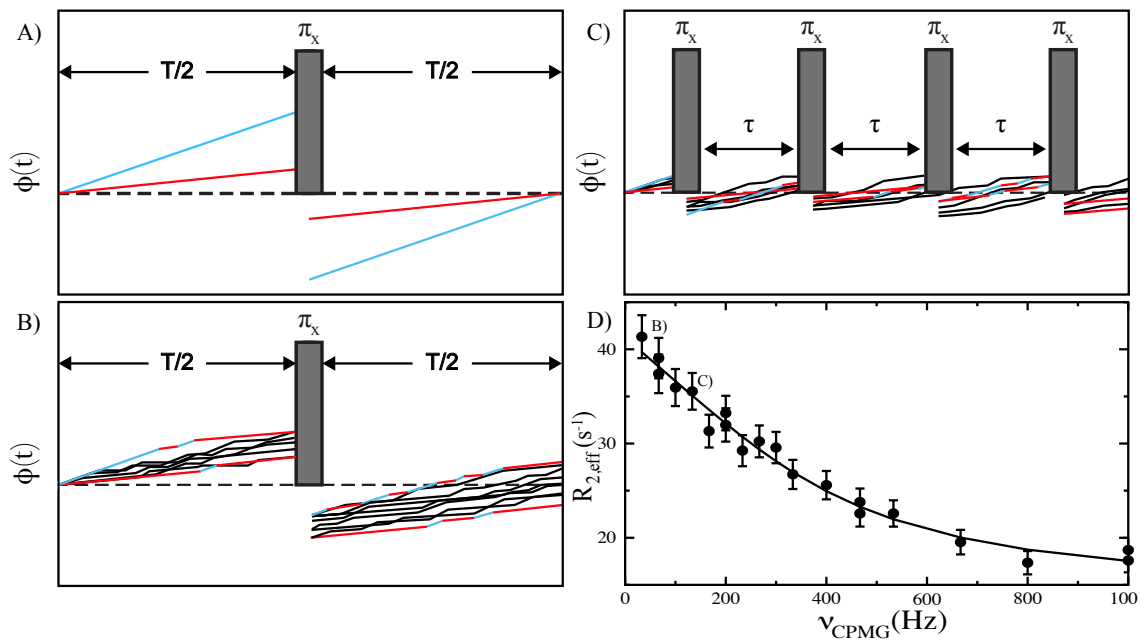

Figure 3.11: The principle behind the CPMG relaxation dispersion experiment. A-C adopted from [60]. Nuclear probes, in state, $a$ and $b$, resonate with different frequencies $\omega_{a}$ (red) and $\omega_{b}$ (cyan). After a time $t$ the accumulated phase is $\phi=\omega t$. A) One spin echo applied on an ensemble of spins, without chemical exchange, perfectly refocuses the spins, the effective relaxation, $R_{2, \text { eff }}$, is very low. B) One spin echo applied on an ensemble of spins, with two-state chemical exchange where the spins stochastically changes between state $a$ and $b$, is not able to

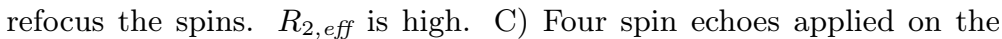
same ensemble as in $\mathrm{B}$ ), refocuses the spins more. $R_{2, \text { eff }}$ is lower. D) A dispersion curve of an ${ }^{15} \mathrm{~N}$ from the kinase domain of EphB2. The effective relaxation, $R_{2, \text { eff }}$, is plotted against the applied rate of the spin-echo, $\nu_{C P M G}$. The data points originating from the rates shown in B) and C) is indicated. As can be seen a high value of $\nu_{C P M G}$ is needed

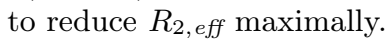

possible to detect any exchange. The limiting factor for fast exchange is set by how fast the pulses may be applied without damaging the equipment. The CPMG relaxation dispersion experiment has been applied to many different nuclei of proteins where some are more straightforward to measure, ${ }^{15} \mathrm{~N}$ [55] and ${ }^{13} \mathrm{CO}$ [61], and others such as ${ }^{1} \mathrm{HN}$ [62], ${ }^{1} \mathrm{H}^{\alpha}$ [63], ${ }^{1} \mathrm{H}^{\text {side-chain }}$ [64], ${ }^{13} \mathrm{C} \alpha$ [65] and ${ }^{13} \mathrm{C} \beta$ [66] need specifically labeled proteins (described in 3.3) due to artifacts caused of scalar or dipolar couplings. The CPMG experiment has been an important experiment for this thesis and is used in all Papers except one. 


\subsection{Specific Isotopic Labeling}

The extraction of most relaxation rates is dependent on magnetic isolation of the desired nucleus so it is only dependent of one relaxation process. Cross-correlation makes the relaxation decays multi-exponential and therefore non-accurate relaxation parameters will be extracted. For CPMG experiments, similar problems are caused by the scalar coupling. In many applications this is taken care of by applying a $\pi$-pulse, inverting the dipole field of the coupled nucleus. For the amide ${ }^{15} \mathrm{~N}$ this is sufficient because its relaxation is dominated by the interaction with the coupled proton and it is also isolated from other ${ }^{15} \mathrm{~N}$. The cases of ${ }^{1} \mathrm{H}$ and ${ }^{13} \mathrm{C}$ are much more complicated and the inverting technique often fails, hence the need for selective isotopic labeling.

For CPMG relaxation dispersion experiments, the isotopic labeling strategy strives to magnetically isolate the desired nucleus, by removing adjacent isotopes of the same kind to reduce homonuclear scalar couplings [62-66]. A useful selective labeling scheme fulfills as many of the following criteria as feasible; the precursors should be as cheap as possible, the labeling at the desired position should be as high and that at undesired positions as low as attainable, the protocol should be easy to use, the total protein yield should be high and the fewest different protein samples possible, for the desired experiment battery, should be necessary to produce. Many of these criteria are competing as evident from Paper IV, which compares two different precursors to evaluate the specific ${ }^{13} \mathrm{C}$ labeling at $\mathrm{C} \alpha$ for $\mathrm{CPMG}$ studies.

Relaxation experiments are not the only case when specific isotopic labeling is necessary, other examples are methyl group labeling for very large systems [67], segmental labeling for multi domain protein studies [68] and amino acid selective labeling and unlabeling for protein assignments [69].

\subsubsection{Amino Acid Synthesis in E. coli}

Most NMR samples for protein NMR are produced by overexpression in Escherichia coli (E. coli). To be able to predict which amino acid precursors are useful for a specific labeling scheme the biosynthesis of amino acids needs to be considered. All amino acids are produced by transamination of an amide group from glutamine or glutamic acid to the corresponding $\alpha$-ketoacid where the $\mathrm{H} \alpha$ is taken from the solvent. The precursors of the $\alpha$-ketoacid is dependent of the type of amino acid and are produced either as intermediates in glycolysis, tricarboxylic acid cycle or pentose phosphate pathway. For a complete description of these synthesis pathways the reader is referred to Voet and Voet [70] or Gottschalk [71]. Important for selective isotopic labeled proteins is that $E$. coli may strive and nourish from many 
different chemicals and that the different positions in the amino acids in principle originates from specific positions in the precursor. However, the biosynthesis is complex in itself and side reactions happen, which reduces predictability and complicates the labeling scheme. These processes result in scrambling; the main labeling path is not the only one occurring. To avoid scrambling it is possible to use genetically changed bacteria where some enzymes are knocked out to cancel out undesired pathways [66].

\subsection{NMR Studies of Large Proteins}

In solution NMR spectroscopy the signals are dependent on the fast rotation, called tumbling, of molecules in solution. Smaller molecules tumble faster than larger ones and therefore larger proteins cause weaker and broader peaks and the longer the experiment, the greater the effects of this problem. By introducing some tricks in the experiment settings it is possible to extend the upper size limit for studying proteins by NMR. These techniques includes excluding the largest source of relaxation, the protons, if possible increase the temperature to increase tumbling rate and to use experiments that are designed for the properties of large proteins. Another problem is that large proteins have more atoms and therefore more peaks that should be fitted into the same signal space as small proteins. This makes the spectra crowded and the peaks may be hard to distinguish from each other, which leads to demanding evaluation of all experiments. Linking the chemical shifts of more nuclei to the same signal, extending the dimensions of the experiment, may resolve the peaks but this results in longer pulse sequences and lower sensitivity, which is already a problem. NMR studies of large proteins are challenging, but improvements during the last decades, both in techniques and equipment, have increased the possibilities [72-75].

\subsubsection{TROSY}

Transverse relaxation optimized spectroscopy (TROSY) is a set of techniques, applicable to most NMR experiments, to reduce relaxation for large proteins $[72,76,77]$. For small proteins this method reduces sensitivity because some useful magnetization is thrown away, but for proteins larger than $20-30 \mathrm{kDa}$ it is necessary for having detectable magnetization in the end of the experiment. In standard experiments, heteronuclear decoupling is applied during proton detected acquisition to quench the splitting of the signal into two peaks. The splitting originates from coupling to the amide ${ }^{15} \mathrm{~N}$. The relative widths of the peaks depend on the cross-correlation between the CSA and the heteronuclear dipole-dipole interaction and one of the peaks is considerably narrowed, due to slower relaxation, compared with the other. 
The TROSY techniques therefore use acquisition of the NMR signal without heteronuclear decoupling to be able to select the slowest relaxing ${ }^{1} \mathrm{HN}$ component. The pulse sequences are carefully designed to let the magnetization pass coherence with favorable relaxation mechanism, which reduces relaxation during the pulse sequence. The protein is extensively deuterated (described in 3.4.2) to reduce relaxation that is not participating in the favorable cross-correlation cancelation. Because CSA is dependent on the magnitude of the external magnetic field, the cross-correlation and consequently the TROSY-effect, is larger at $18 \mathrm{~T}$ than $14 \mathrm{~T}$ and optimal are fields at $20-25 \mathrm{~T}$.

\subsubsection{Deuteration}

Regular hydrogen, ${ }^{1} \mathrm{H}$, nuclei only have one proton, nothing else. The deuteron, ${ }^{2} \mathrm{H}$, a deuterium nuclei, consists of one proton and one neutron, altering the nuclear spin quantum number from $1 / 2$ to 1 , which changes its magnetically properties considerably. This may be used in many applications, such as to isolate protons in relaxation measurements (described in 3.3) and for example in deuteration exchange experiments where proton labeled protein is dissolved in deuterium buffer and the decreasing signal as a consequence of proton-deuteron exchange is detected to give information about which areas of the protein are most exposed to the solvent [78]. For this thesis, and maybe also for most users, deuterium is used to increase sensitivity when studying large proteins. The ${ }^{1} \mathrm{H}-{ }^{13} \mathrm{C}$ dipolar interaction dominates the relaxation of ${ }^{13} \mathrm{C}$ spins where this bond is present and the relaxation of ${ }^{1} \mathrm{HN}$ arises to $\sim 40 \%$ from ${ }^{1} \mathrm{H}$ close in space. Deuterons have a gyromagnetic ratio, 6.5 -fold smaller than the proton resulting in 16 -fold less effective relaxation of the adjacent nuclei. The difference between standard and deuteration optimized, triple resonance experiments, used in the assignment process, is the need for decoupling of the scalar coupling between the ${ }^{13} \mathrm{C}$ and the attached deuteron when magnetization is in the transverse plane of the carbon.

To produce deuterated proteins, protein expression is performed in minimal media where the solvent is ${ }^{2} \mathrm{H}_{2} \mathrm{O}$ (heavy water). For a protein with $\sim 99 \%$ deuteration also the carbon source needs to be deuterated. As described in 3.1.6, it is possible to increase sensitivity by starting and ending the experiment with magnetization on the proton. To make sure that all the amide deuterons are exchanged to protons, the protein is therefore unfolded and refolded in ${ }^{1} \mathrm{H}_{2} \mathrm{O}$ based buffers. Two disadvantages of production of deuterated proteins are the higher cost and the longer expression time compared with protonated proteins. 


\subsection{Fast Sampling Techniques}

One of the drawbacks of NMR spectroscopy is the low sensitivity and consequently the need to repeat the pulse sequence multiple times, resulting in long experiment times. Both a problem for fully booked spectrometers and proteins with limited stability. Another source of long measuring time is the need for repeating the pulse sequence with increasing evolution delays in the indirect dimensions for satisfactory resolution. A few well-established techniques have been developed to decrease the total time of the experiment. The band-selective excitation short-transient (BEST) technique uses band-selective pulses centered on the amide region instead of hard pulses to speed up the longitudinal proton relaxation between scans [79], reducing the delay in-between repetitions, which decreases the experiment time considerably.

\subsubsection{Non-Uniform Sampling}

The non-uniform sampling (NUS) strategy reduces measuring time by not detecting every single FID as in the standard case. Instead it is possible to randomly sample just a fraction of that data and then reconstruct the regular spectra from the much faster experiment. The randomness of the data points are weighted with some pre known information such as relaxation rates and scalar couplings [80]. The standard way of processing an NMR experiment is the Fourier transform, but because it requires data acquired regularly spaced it is not possible to solely use it for NUS data. Instead other processing methods, for example multi-dimensional decomposition processing (MDD), are needed [81]. MDD makes the assumption that the NMR signal is completely defined by its line shape in all spectral dimensions, meaning that three separate one-dimensional vectors may describe a three-dimensional peak. Because the line shape of the NMR peaks are known, the full spectrum may be reconstructed by prediction of the missing data together with normal processing strategies.

In Paper III CPMG relaxation dispersion data have been resolved into three dimensions and the NUS scheme have been used to considerably reduce experimental time. 


\section{Chapter 4}

\section{Data Analysis}

In many divisions of science, massive amounts of data are collected. NMR spectroscopy is no exception. To be able to compare data and make conclusions, the data normally need to be converted and/or presented in a more understandable way. An important analysis is data fitting because almost always a limited number of data points can be collected. To find the model that best describe the data the model needs to be optimized. All of this may be done in many ways and some of the most important for this thesis will be presented herein. To facilitate and speed up data analysis there is a need for dedicated computer programs. Two of the papers in this thesis present software aiming to simplify the analysis of data collected by NMR spectroscopy, COMPASS for resonance assignments and PINT for peak integration. However, data analysis is used to a large extent in all papers.

\subsection{Data Fitting}

Data fitting is the process of optimizing models to data and evaluating the results. The process aims to minimize a target function, often the weighted least square deviation function, $\chi^{2} \cdot \chi^{2}$ describes the difference between the collected data and the model, as follows

$$
\chi^{2}=\sum_{i=1}^{n}\left(\frac{y_{i}-y\left(\Phi_{1}, \Phi_{2}, \ldots, \Phi_{k}\right)_{i}}{\sigma_{i}}\right)^{2}
$$

where $y_{i}$ is the measured value with error $\sigma_{i}$ and $y\left(\Phi_{1}, \Phi_{2}, \ldots, \Phi_{k}\right)_{i}$ the model value for data point $i . \Phi_{x}$ are the $k$ number of model parameters determining the model [82].

One fitting method is the gradient descent. The fitting starts with the model defined by the initial model parameters, set by default or estimated 
by the user. The target function and the gradient of the target function are calculated and the parameters of the model function are changed in the direction of the negative of the gradient. This is repeated until no change lowers the value of the target function, a minimum is reached and the data have been fitted. This method may however be rather slow and normally it is more efficient to use the Levenberg-Marquardt algorithm also called the damped least square algorithm. This utilizes the gradient descent (used far from the minimum) together with a mixture of it and the inverse-Hessian algorithm (closer to the minimum) [82]. Normally a limit is set of allowed numbers of iterations before the fit is considered to have failed and no minimum was found.

One problem with data fitting is to determine if the minimum is the desired global minimum or an undesired local minimum. There are methods with probability to occasionally take a route that increases the target function, sometimes resulting in finding a different minimum. Another strategy is to perform a grid search, starting the fit with different model parameters, helping to find the global minimum.

In Paper I $\chi^{2}$ is used, in the software COMPASS, as an indicator on how well the connected resonance fragments matches different parts of the protein sequence, in Paper II, in the software PINT, $\chi^{2}$ indicates the success of the line shape fit and in Paper III-IV it has been used to evaluate data.

\subsection{Error Estimation}

For almost all data evaluation, especially data fitting, the errors of the data points need to be correctly estimated and the method depends on the amount of available data as well as the nature of the data. The most statistically robust error is the standard error, which is the standard deviation of the sample distribution [83]. This requires that every measurement has been performed multiple times, which is often not possible due time constrains. Errors may instead be estimated from the standard deviation of duplicated measurements, on condition that the standard deviation for different measurements can be assumed to be the same. Given that enough duplicates have been measured it is possible to estimate the error for one data set, which for example may be one residue in a protein. With few duplicates, many data sets (the entire protein) need to be considered to get enough statistics in the error. Also in this case the variation should be the same for different measurements [2]. Resampling is another method, where the error is estimated by performing the analysis multiple times with slightly modified data sets. This is either done by performing the analysis with $M$ numbers of data points from an $N$-size sample $(M<N)$, called the jackknife method [82], or by randomly drawing $N$ data points from an 
$N$-size sample, called bootstrapping, where it is possible to draw the same measured data point multiple times [82].

In Paper II, which describes the peak integration software PINT, the duplicate data point method is used, when possible, to estimate the errors in the integrated volumes. For estimating the errors of the converted parameters, for instance the relaxation rate constants, the jackknife method is used. In Paper III different error estimation methods are compared.

\subsubsection{Error Propagation}

If the error of one variable has been estimated and the variable needs to be converted also the error requires appropriate conversion, called error propagation. In this thesis it has been done for the calculation of the effective relaxation rates for estimated peak volumes, for example. For a function, $f$, of one variable, $x$, the error $\Delta f$ should be propagated as

$$
\Delta f \approx\left|\frac{d f}{d x}\right| \Delta x
$$

where $\Delta x$ is the error in the variable $x$ [83]. For the function $f(x, y, \ldots)$, under the assumption that the variables are uncorrelated, the error is calculated according to

$$
|\Delta f| \approx \sqrt{\left(\frac{\partial f}{\partial x}\right)^{2} \Delta x^{2}+\left(\frac{\partial f^{2}}{\partial y}\right) \Delta y^{2}+\ldots}
$$

where $\Delta x$ and $\Delta y$ are the estimated errors in the respective variables (in this case estimated from duplicate data points).

\subsection{Evaluating Fits}

Visual inspection is one way to evaluate if there is a difference between two data sets or whether there is a difference in how well two separate models describe a data set. The human eye and brain are excellent at finding patterns and deviations from them, but often it is useful to have a more statistically reliable method and then statistical tests are helpful. Most of the nomenclature and theory in this section have been taken from 100 statistical tests by Gopal K. Kanji [84].

The test procedure of a statistical test is to:

1. Formulate the hypothesis

2. Calculate a test statistic 
3. Choose a critical region

4. Decide the size of the region or significance level

5. Compare if the test statistic is well into the chosen region or just within it

The hypothesis is formulated so it implies no difference between data sets or models. The test is then constructed so that the hypothesis should be discarded if it is very improbable that it is true. The test statistic is calculated to help determining this. If the test statistic is outside of the critical region the hypothesis may be discarded. The significance level is approximately describing how large the risk is for making incorrect conclusions. In this thesis $F$-tests and $t$-tests have been used to determine if a nucleus experiences chemical exchange or not.

One thing to consider when choosing type of statistical test is how robust it is. The robustness of a test is described by how sensitive it is for deviations from the requirements that are described for that test. For example, many tests demand the tested variable to be normal-distributed and a robust test will be correct even if this is only approximately true.

\subsubsection{F-Test}

The $F$-test may be used to test the hypothesis that a data set in a regression analysis follows the simpler of two proposed linear models that are nested within each other. If the same data set has been fitted to two different models where the simpler model is a reduced form of the more complicated one, it is possible to check if it is statistically significant to discard the simpler model in favor of the more complicated one. The test statistic is

$$
F=\frac{\chi_{1}^{2} /\left(n_{1}-1\right)}{\chi_{2}^{2} /\left(n_{2}-1\right)}
$$

where $\chi_{1}^{2}$ and $\chi_{2}^{2}$ are the target functions calculated by equation 4.1 for the simpler and more complicated model respectively and $n_{1}$ and $n_{2}$ are the degrees of freedom for the two models [82].

\subsection{2 $t$-Test of a Correlation Coefficient}

This test is designed to test if the sample correlation coefficient is significantly different from zero. Both $x$ and $y$ should be normal-distributed with a linear relationship. The data set with $n$ points $\left(x_{i}, y_{i}\right)$ has the correlation coefficient, $r$, calculated as

$$
r=\frac{\sum\left(x_{i}-\bar{x}\right)\left(y_{i}-\bar{y}\right)}{\left[\sum\left(x_{i}-\bar{x}\right)^{2} \sum\left(y_{i}-\bar{y}\right)^{2}\right]^{\frac{1}{2}}}
$$


4 .

where $\bar{x}$ and $\bar{y}$ is the mean value of the respective variables. The test statistic $t$ follows Student's $t$-distribution with $n-2$ degrees of freedom and is

$$
t=\frac{r}{\sqrt{1-r^{2}}} \cdot \sqrt{n-2}
$$

This has been used in Paper IV to test if a nucleus undergoes chemical exchange, in that case the correlation between the two parameters are approximately exponential and if the logarithm of the $y$-value is taken the correlation between $x$ and $y$ is possible to test by the $t$-test [84]. 
4. 


\section{Chapter 5}

\section{Summary of My Work}

Proteins are not static blocks but dynamical molecules with interesting excited states that are important for example for catalysis and protein interactions. The main foci of this thesis are protein dynamics and the use of solution nuclear magnetic resonance (NMR) spectroscopy, to characterize it. This thesis contains four papers of improved methods and one paper about dynamical properties of the activation of the kinase domain of ephrinB receptor 2 (EphB2).

\subsection{Paper I}

Protein resonance assignments are the link between the NMR signals and the nuclei in the protein. They are critical for almost all applications of protein NMR spectroscopy and to achieve them is often a time consuming manual task. Software has been developed for automation of the process [32-35] but often with unsatisfactory success rates and with errors, especially for large proteins with limited data sets. Paper I presents the interactive software COMPASS (COmputer-aided Matching and Peak ASSignment) developed to take advantage of statistics, the calculation power of a computer and the experience and flexibility of the user. Input to the program is chemical shifts from triple resonance experiments, which, in the Label module, are grouped into spin systems of all resonances scalar coupled to a specific amide proton. In the Analyze module, the spin systems are linked into peptide fragments, the chemical shifts of which subsequently are compared to statistical values from the chemical shift database RefDB [85], to calculate the probable position in the protein sequence. The user obtains the results from Analyze as statistical probabilities, the reduced $\chi^{2}$, and assigns the chemical shifts to the nuclei in the protein, by choosing the best results in the Assign module. The workflow of COMPASS is schematically described in figure 5.1. For the 


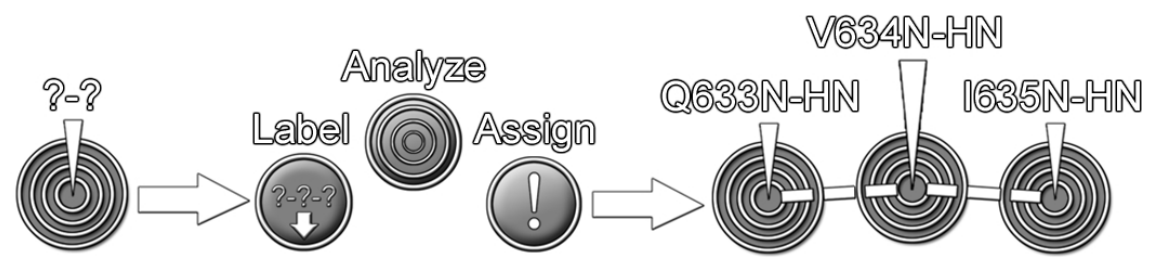

Figure 5.1: Schematic description of the resonance assignment process by COMPASS, from unlabeled chemical shifts to connected peptide fragments.

tripeptide in figure 5.1 the process starts by lists of uncorrelated chemical shifts that are then grouped together into unreferenced spin systems, 103, 64 and 203, in the Label module. These are then connected in the Analyze module, by matching their chemical shifts, to a tripeptide fragment, 20364-103. The tripeptide fragment is then compared with the chemical shifts in the RefDB database to be able to combine the chemical shifts to different positions in the sequence of the protein. The software then presents the statistical scores for the spin systems to be assigned to positions in the protein and the user may confirm that the best match is: Q633, V634 and I634, in the Assign module.

Compared with the time consuming manual assignment procedure COMPASS provide a faster process without entrusting the control to the computer, resulting in more accurate and complete results compared to other automated and semi-automated software. Included is the possibility to compensate for chemical shift differences as a consequence of deuteration, especially useful for large proteins. Automatic software for resonance assignments usually has problems with assigning proteins with lower degree of signals than anticipated, which is often the case for large proteins. Zuiderweg et al. state that their program, EZ-Assign, outperforms other software published (2013) on these occasions [35]. In Paper I it is shown that COMPASS executes even better, for the protein thiopurine methyltransferase [86] with high degree of missing data. COMPASS has been developed with user friendliness as a key concern with extensive error handling and has been implemented for Linux, Mac OS X and Windows.

\section{$5.2 \quad$ Paper II}

This paper presents the software PINT (Peak INTegration) developed for peak integration and conversion of peak volumes to physical quantities. In NMR experiments peaks correspond to the measured signal. Especially 

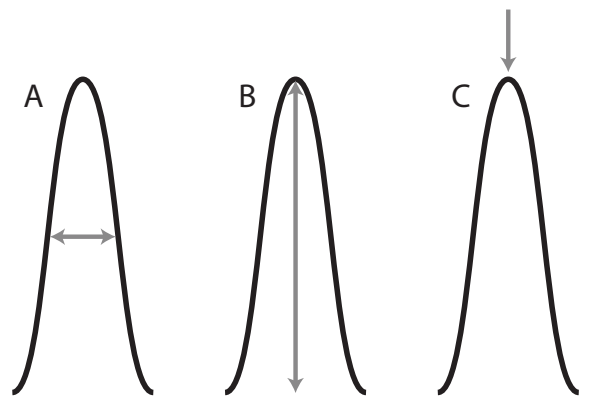

Figure 5.2: Schematic drawings of one-dimensional peaks where the characteristics that are fitted by PINT are pointed out, A) line width B) intensity and C) chemical shift.

for experiments evaluating protein dynamics, the correct estimation of peak volumes is crucial. PINT integrates peaks, from two-dimensional or pseudothree-dimensional spectra, by minimizing the sum of squared residuals between the experimental data and a line shape. The line shape of the peak is defining the chemical shift of the peak, the maximum intensity of the peak and the line width of the peak, shown in figure 5.2. PINT can convert the peak volumes to quantities such as relaxation rates, hydrogen exchange rates and the heteronuclear NOE. The output is the volume of the peak, files listing the converted quantity as well as plots for easy inspection of the fit. PINT's main advantages are its possibility to integrate multiple overlapped peaks, the easy way to inspect and compare the fitted curves to the experimental data and converting options. Without competent integration software such as PINT, it is not feasible to analyze overlapped peaks in relaxation experiments, used to investigate protein dynamics, and some potentially important information may get lost.

\subsection{Paper III}

Some proteins have low resolution in two-dimensional NMR spectra resulting in complicated or sometimes impossible evaluation of the results. The two-dimensional spectrum is the base of many standard relaxation experiments. One way to deal with overlapped peaks is to resolve the signals into three dimensions. Two three-dimensional versions of the CPMG relaxation dispersion experiment detecting millisecond dynamics at ${ }^{15} \mathrm{~N}$ and ${ }^{13} \mathrm{CO}$ are described in Paper III. The pulse sequences were tested on a wellcharacterized system, the SH3 domain from the yeast protein Abp1p [87]. To decrease measuring-time, eight and five percent of the data, compared 
to the standard experiment, were sampled using non-uniform sampling, and the standard data set were reconstructed by multi-dimensional decomposition co-processing (co-MDD) [88]. The extracted exchange parameters were comparable to the ones obtained from the standard experiments, which confirmed the performance of the experiment. These experiments are most suited for small to medium sized proteins with poor ${ }^{15} \mathrm{~N}-{ }^{1} \mathrm{HN}$ resolution.

\subsection{Paper IV}

The importance of protein dynamics together with the possibility to determine the structure of a protein solely by the chemical shifts $[29,30]$ have driven the development of experiments to detect chemical shifts of the excited state of all backbone nuclei. Some experiments need labeling of specific nuclei to avoid artifacts in the results. Many of the precursors added to the growth medium in order to obtain site-specific labeling have limitations and it is worth studying different possibilities. In Paper IV the use of $\left[2-{ }^{13} \mathrm{C}\right]-$ glycerol for selective labeling of $\mathrm{C} \alpha$ positions has been investigated as an alternative to $\left[2-{ }^{13} \mathrm{C}\right]$-glucose [65] because theoretically this may result in twice the amount of incorporated ${ }^{13} \mathrm{C}$ at $\mathrm{C} \alpha$ positions, without incorporation at $\mathrm{C} \beta$. The reason for this is that one of three carbons is ${ }^{13} \mathrm{C}$ in $\left[2-{ }^{13} \mathrm{C}\right]$-glycerol compared with one of six carbons in $\left[2-{ }^{13} \mathrm{C}\right]$-glucose. One glycerol molecule is then catabolized in the metabolism of E. coli to the precursor of one amino acid and this is labeled with ${ }^{13} \mathrm{C}$ at $\mathrm{C} \alpha$. The glucose molecule however, is divided into two amino acid precursors with only one of them labeled with ${ }^{13} \mathrm{C}$ at $\mathrm{C} \alpha$ (see figure 5.3). Incorporation of ${ }^{13} \mathrm{C}$ at $\mathrm{C} \alpha$ positions are indeed doubled and the levels of ${ }^{13} \mathrm{C} \beta$ were low enough to extract accurate $\mathrm{C} \alpha$ chemical shifts of the excited state. The glycerol strategy presented herein lends itself to proteins with sensibility problems due to solubility issues, because they would benefit from increased concentration of ${ }^{13} \mathrm{C}$ at $\mathrm{C} \alpha$ at a limited protein concentration.

\subsection{Paper V}

In this paper the kinase domain of ephrinB receptor 2 (EphB2) has been studied in regard to activation. The Eph receptors are implicated in various forms of cancers [17] and neurodegenerative diseases such as Alzheimer's [18] and therefore their regulatory mechanism is interesting to study. Binding of its ligand, the ephrin, induces autophosphorylation of the intracellular parts and multimerization of the receptor-ligand cluster, activating the receptor. The kinase domain has previously been studied by X-ray crystallography and NMR spectroscopy [89], which herein was followed up by further investigations of dynamics and multimerization properties. ${ }^{15} \mathrm{~N}$ CPMG relaxation 


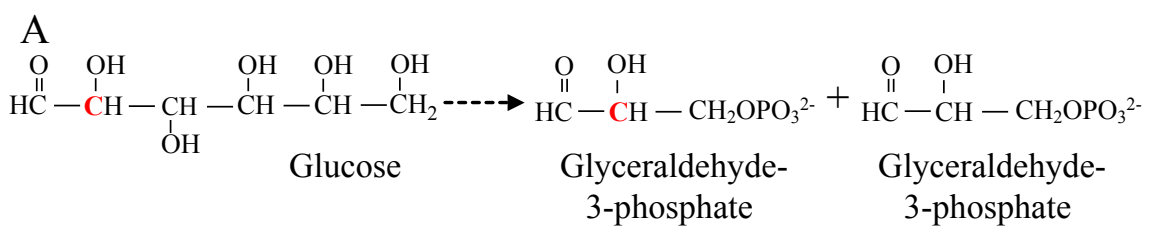

B

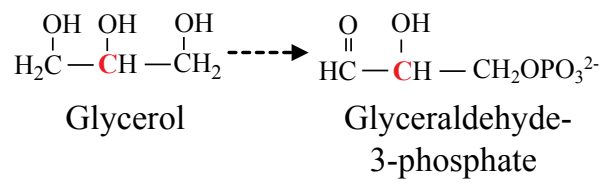

Figure 5.3: Molecular structure of glucose, glycerol and the amino acid precursor glyceraldehyde-3-phosphate (GAP). The red carbons indicates ${ }^{13} \mathrm{C}$ and the dashed arrows multiple catabolic steps. In $\mathrm{A}$, one $\left[2-{ }^{13} \mathrm{C}\right]-$ glucose is converted to one $\left[2-{ }^{13} \mathrm{C}\right]-\mathrm{GAP}$ and one GAP. In $\mathrm{B}$, one [2$\left.{ }^{13} \mathrm{C}\right]$-glycerol is converted to one $\left[2-{ }^{13} \mathrm{C}\right]$-GAP. For thorough biosynthetic pathways, see [65] and Paper IV.

dispersion experiments detected millisecond dynamics in active forms of the kinase domain of EphB2 but not in inactive forms, which confirms the hypothesis that the EphB2 kinase domain is not activated by a major change of structure but rather by the possibility to dynamically sample different conformations $[89,90]$. Another important finding was that the transverse relaxation rate constant was significantly higher for active constructs than inactive ones. This was interpreted as active forms of the kinase domain self-associating into multimers. Other parts of the receptor have previously been associated with multimerization [91-95] but this study shows that the kinase domain also plays a role in the multimerization process, providing docking sites for down-stream signaling proteins. 
5. 


\section{Chapter 6}

\section{Conclusions and Perspectives}

Protein dynamics are essential for protein function and solution NMR spectroscopy is the prime method to study protein dynamics at atomic resolution. This thesis aims to improve and extend the available techniques as well as showing that protein dynamics are important for activation of the kinase domain of ephrinB receptor 2 (EphB2). Central for the thesis is the CPMG relaxation dispersion experiment [54] (described in 3.11), an excellent method to detect millisecond dynamics, important for many biologically important processes [2-5].

The software COMPASS, presented in Paper I, shortens the time for the crucial but usually time consuming first step in protein NMR spectroscopy, the manual assignments of the NMR signals to the nuclei of the protein, as well as improves the success rate compared to other software [32-35]. Although COMPASS has a broader application than protein dynamics it should be stressed that more complete degree of assignment increases the possibilities to interpret the dynamical data and that faster process time liberates time for thorough dynamical analysis. COMPASS is under improvement and has been speeded up by multithreading, which enables the software to run in parallel on multiple processor cores, to sped up the analysis process. Flexibility in the Assign module has also been improved by for example adding the possibility to search for shifts that incorrectly have been labeled to another spin system. Including a function that automatically processes partially preassigned proteins has been implicated to accelerate addition of new spin systems or assigning a mutant, for example. In the future, useful implementations would be the addition of complementing experiments such as 4D HNCACO, 4D HNCOCA, NOESY or TOCSY, extending the spin systems for more matching options, direct visual inspection 
6.
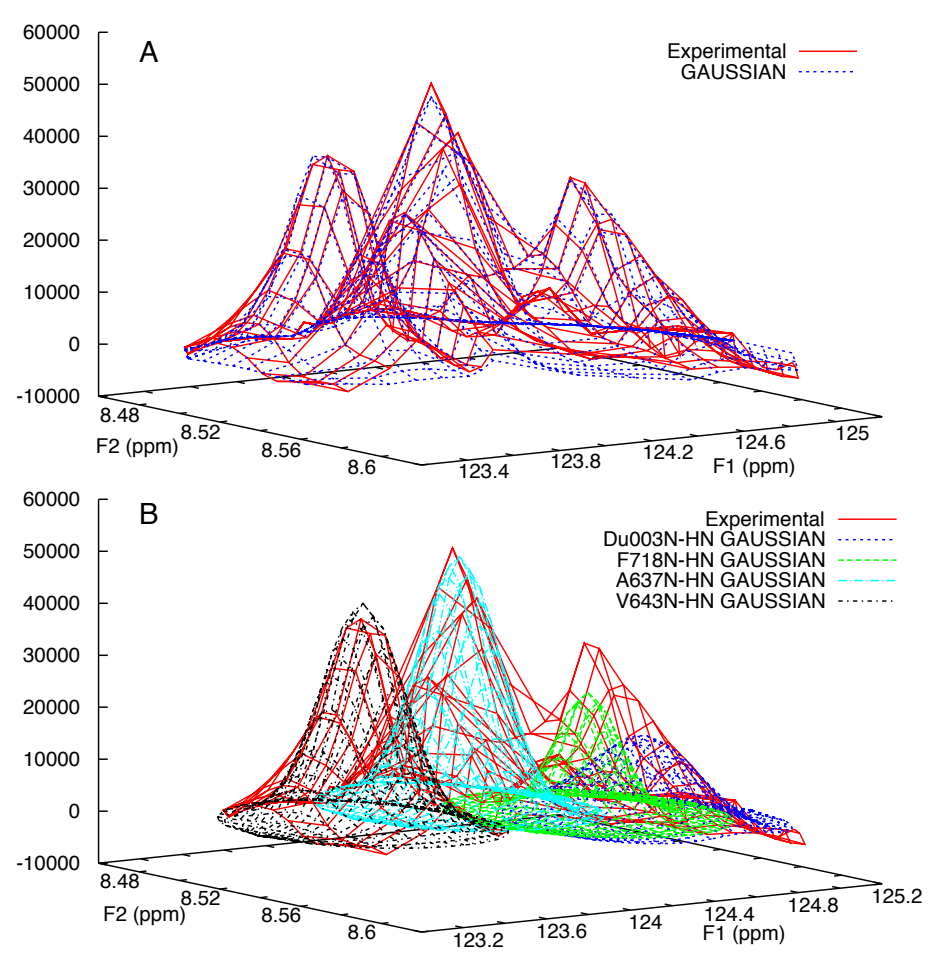

Figure 6.1: Plot view of four overlapped peaks from EphB2 kinase domain integrated by PINT. The experimental data are plotted in red. In A) the sum of the fitted peaks is shown in blue. In B) the individual fitted peaks are plotted in blue, green, cyan and black, respectively.

of the spectra in COMPASS for easier control of the correctness of the spin system as well as improved algorithms for the Label module, which groups unlabeled chemical shifts into spin systems.

The software PINT (Peak INTegration), Paper II, is more specialized to dynamical studies and especially evaluates relaxation experiments, for example CPMG relaxation dispersions, by integration of the NMR signals and conversion of the peak volumes to physical quantities. There are plans to extend the applications to evaluation of titrations and protein interactions by simultaneously fitting peaks with different chemical shifts between spectra. At Linköping University, PINT is used in all projects involving NMR studies of protein dynamics. Already applied improvements since publication are multithreading and optimization of the numerical algorithms. For the case of EphB2, described in the paper, the time for integration, of 241 
peaks in an $R_{1 \rho}$ experiment comprising 15 relaxation delays, has decreased from approximately six minutes to thirty seconds. There is also a refined plotting option for overlapped peaks rendering graphs for both individually fitted peaks as well as the sum of all the peaks (see figure 6.1). Ongoing work is to upgrade the usability of the program by refining the graphical interface and to implement integration of peaks from three-dimensional and pseudo-four-dimensional spectra.

Paper III describes two pulse sequences detecting millisecond dynamics, by CPMG relaxation dispersion, with high resolution to decrease problems for proteins with poorly dispersed two-dimensional spectra. The nonuniform sampling strategy was applied to decrease measuring time. One example of proteins with crowded spectra is the intrinsically disordered proteins (IDPs). To further characterize protein dynamics the three-dimensional strategy from the methodology may be transferred to experiments detecting $R_{1}, R_{2}$ and the heteronuclear NOE (described in 3.2.1). For IDPs these parameters are often more interesting to study than millisecond dynamics.

Heavily overlapped peaks, in for example pseudo-three-dimensional relaxation experiments, may be dealt with by higher resolution experiments, described in Paper III, or peak integration software such as PINT, described in Paper II. PINT may handle peaks overlapped to a certain extent but there is a limit. Especially in cases where both chemical shifts are almost identical the fitting procedure is often unsuccessful. Those cases would benefit from higher resolution. However, there is naturally a limit also for the pseudofour-dimensional experiments, like lower sensitivity, reducing the possibilities to use them for larger proteins. The user may in those cases instead use the two-dimensional version of the experiment and increase the resolution in the indirect dimension to be able to partly resolve the peaks to facilitate the peak integration by PINT.

In Paper IV, a strategy that specifically labels $\mathrm{C} \alpha$, but not $\mathrm{C} \beta$, with ${ }^{13} \mathrm{C}$, for most residues is evaluated. This is necessary for artifact free measuring of $\mathrm{C} \alpha$ chemical shifts of excited states, by CPMG relaxation dispersion experiments. Proteins are produced with $\left[2{ }^{13} \mathrm{C}\right]$-glycerol as carbon source, which theoretically doubles the incorporation degree compared to previously described strategy with $\left[2-{ }^{13} \mathrm{C}\right]$-glucose [65]. The results show that this is true but at the expense of slightly increased levels of artifacts, mostly due to simultaneously ${ }^{13} \mathrm{C}$-labeling at $\mathrm{C} \beta$. One difference between expressing protein with glycerol, as carbon source, compared with glucose is the slower growth rate of the bacteria. This may be one of the reasons behind the artifacts because the longer time the bacteria are growing the more time they have for scrambling the isotopes, by minor metabolic pathways. If there are bacteria that are more competent to grow on glycerol, that may solve this. There is another precursor that could be used, the $\left[2,5-{ }^{13} \mathrm{C}\right]-$ glucose that theoretically would give the same incorporation level of $\mathrm{C} \alpha$ 
as $\left[2-{ }^{13} \mathrm{C}\right]$-glucose. That precursor would probably also give faster bacteria growth, which may reduce artifacts, but it is however more expensive.

In Paper $\mathrm{V}$ it was concluded that active forms of the kinase domain of EphB2 are more dynamic in the millisecond time frame and also more prone to form multimers than inactive forms. For more detailed conclusions of the multimer structure, small angle X-ray scattering (SAXS) [96] experiments are planned in the near future. The SAXS measurements will hopefully give a low resolution structure to shed light upon the biological relevance of the multimers, both in respect to the constructs we use as active protein mimics and related to the rest of the receptor protein. For deeper understanding of the millisecond dynamics, CPMG relaxation dispersion experiments at different concentration of the cofactor $\mathrm{Mg}^{2+}$ as well as the substrate adenosine triphosphate (ATP), or a more stable analog would be very interesting to perform. The majority of the nuclei, which show millisecond dynamics, have been detected in the region of the ATP binding pocket. If this pocket opens and closes, to facilitate ATP binding, it is reasonable to expect the nature of the dynamics to change in the presence of the substrate. The software COMPASS and PINT described in Paper I and II was used to assign the NMR signals and to evaluate protein dynamics in this project. The size of the studied protein was too large and the quality of the spectra collected on the samples were to low to be able to use the techniques described in $\mathrm{Pa}$ per III and IV, but those methods would likely have resulted in interesting results, if possible to perform.

To conclude, many techniques need to be used in the study of proteins and structural biology. NMR will in the future still be the technique of choice to characterize protein dynamics. The increasing number of methods available, included the ones described in this thesis, will facilitate for scientists to ask and answer even more complicated questions. 


\section{References}

[1] Jordi Espadaler, Enrique Querol, Francesc X Aviles, and Baldo Oliva. Identification of function-associated loop motifs and application to protein function prediction. Bioinformatics, 22(18):2237-2243, 2006.

[2] Dmitry M Korzhnev, Xavier Salvatella, Michele Vendruscolo, Ariel A Di Nardo, Alan R Davidson, Christopher M Dobson, and Lewis E Kay. Low-populated folding intermediates of fyn SH3 characterized by relaxation dispersion nmr. Nature, 430(6999):586-590, 2004.

[3] Magnus Wolf-Watz, Vu Thai, Katherine Henzler-Wildman, Georgia Hadjipavlou, Elan Z Eisenmesser, and Dorothee Kern. Linkage between dynamics and catalysis in a thermophilic-mesophilic enzyme pair. Nat Struct Mol Biol, 11(10):945-949, 2004.

[4] E. Z. Eisenmesser, O. Millet, W. Labeikovsky, D. M. Korzhnev, M. WolfWatz, D. A. Bosco, J. J. Skalicky, L. E. Kay, and D. Kern. Intrinsic dynamics of an enzyme underlies catalysis. Nature, 438(7064):117-21, 2005.

[5] Jean-Philippe Demers and Anthony Mittermaier. Binding mechanism of an SH3 domain studied by NMR and ITC. J Am Chem Soc, 131(12):4355-4367, 2009.

[6] D Baker and D A Agard. Kinetics versus thermodynamics in protein folding. Biochemistry, 33(24):7505-7509, 1994.

[7] A Malmendal, J Evenas, S Forsen, and M Akke. Structural dynamics in the C-terminal domain of calmodulin at low calcium levels. $\mathrm{J} \mathrm{Mol} \mathrm{Biol,}$ 293(4):883-899, 1999.

[8] V L Schramm. Enzymatic transition states and transition state analog design. Annu Rev Biochem, 67:693-720, 1998.

[9] Daniel A Kraut, Kate S Carroll, and Daniel Herschlag. Challenges in enzyme mechanism and energetics. Annu Rev Biochem, 72:517-571, 2003.

[10] Carlos Salazar and Thomas Hofer. Competition effects shape the response sensitivity and kinetics of phosphorylation cycles in cell signaling. Ann NY Acad Sci, 1091:517-530, 2006.

[11] G Manning, D B Whyte, R Martinez, T Hunter, and S Sudarsanam. The protein kinase complement of the human genome. Science, 298(5600):19121934, 2002. 
[12] S. S. Taylor and A. P. Kornev. Protein kinases: evolution of dynamic regulatory proteins. Trends Biochem Sci, 36(2):65-77, 2011.

[13] Eric D Scheeff and Philip E Bourne. Structural evolution of the protein kinase-like superfamily. PLoS Comput Biol, 1(5):e49, 2005.

[14] A. P. Kornev, N. M. Haste, S. S. Taylor, and L. F. Eyck. Surface comparison of active and inactive protein kinases identifies a conserved activation mechanism. Proc Natl Acad Sci U S A, 103(47):17783-8, 2006.

[15] E. B. Pasquale. Eph-ephrin bidirectional signaling in physiology and disease. Cell, 133(1):38-52, 2008.

[16] M. Genander and J. Frisen. Ephrins and Eph receptors in stem cells and cancer. Curr Opin Cell Biol, 22(5):611-6, 2010.

[17] E. B. Pasquale. Eph receptors and ephrins in cancer: bidirectional signalling and beyond. Nat Rev Cancer, 10(3):165-80, 2010.

[18] M. Cisse and F. Checler. Eph receptors: new players in alzheimer's disease pathogenesis. Neurobiol Dis, 73:137-49, 2015.

[19] K. Kullander and R. Klein. Mechanisms and functions of eph and ephrin signalling. Nat Rev Mol Cell Biol, 3(7):475-86, 2002.

[20] J C Kendrew, G Bodo, H M Dintzis, R G Parrish, H Wyckoff, and D C Phillips. A three-dimensional model of the myoglobin molecule obtained by X-ray analysis. Nature, 181(4610):662-666, 1958.

[21] Soren G F Rasmussen, Hee-Jung Choi, Daniel M Rosenbaum, Tong Sun Kobilka, Foon Sun Thian, Patricia C Edwards, Manfred Burghammer, Venkata R P Ratnala, Ruslan Sanishvili, Robert F Fischetti, Gebhard F X Schertler, William I Weis, and Brian K Kobilka. Crystal structure of the human $\beta 2$ adrenergic G-protein-coupled receptor. Nature, 450(7168):383-387, 2007.

[22] Gale Rhodes. Crystallography Made Crystal Clear, Third Edition: A Guide for Users of Macromolecular Models (Complementary Science). Academic Press, 2006.

[23] Greg Ralston. Introduction to Analytical Ultracentrifugation. Beckman, 1993.

[24] Jacob Lebowitz, Marc S Lewis, and Peter Schuck. Modern analytical ultracentrifugation in protein science: a tutorial review. Protein Sci, 11(9):20672079, 2002.

[25] Malcolm Levitt. Spin dynamics : basics of nuclear magnetic resonance. John Wiley \& Sons, Ltd, Chichester, England Hoboken, NJ, 2008.

[26] Brian Cowan. Nuclear Magnetic Resonance and Relaxation. Cambridge University Press, Cambridge, revised. edition, 2005.

[27] John Cavanagh, Nicholas J. Skelton, Mark Rance, Wayne J. Fairbrother, and Arthur G. Palmer. Protein NMR spectroscopy principles and practice. Academic Press, Amsterdam Boston, 2007.

[28] Silvia Spera and Ad Bax. Empirical correlation between protein backbone conformation and $\mathrm{C} \alpha$ and $\mathrm{C} \beta{ }^{13} \mathrm{C}$ nuclear magnetic resonance chemical shifts. Journal of the American Chemical Society, 113(14):5490-5492, 1991. 
[29] A. Cavalli, X. Salvatella, C. M. Dobson, and M. Vendruscolo. Protein structure determination from NMR chemical shifts. Proc Natl Acad Sci U SA, 104(23):9615-20, 2007.

[30] Y. Shen, O. Lange, F. Delaglio, P. Rossi, J. M. Aramini, G. Liu, A. Eletsky, Y. Wu, K. K. Singarapu, A. Lemak, A. Ignatchenko, C. H. Arrowsmith, T. Szyperski, G. T. Montelione, D. Baker, and A. Bax. Consistent blind protein structure generation from NMR chemical shift data. Proc Natl Acad Sci U S A, 105(12):4685-90, 2008.

[31] Jean Jeener. Lecture (Ampère Summer School, Basko Polje, Yugoslavia). Lecture, 1971.

[32] D E Zimmerman, C A Kulikowski, Y Huang, W Feng, M Tashiro, S Shimotakahara, C Chien, R Powers, and G T Montelione. Automated analysis of protein NMR assignments using methods from artificial intelligence. $\mathrm{J} \mathrm{Mol}$ Biol, 269(4):592-610, 1997.

[33] Arash Bahrami, Amir H Assadi, John L Markley, and Hamid R Eghbalnia. Probabilistic interaction network of evidence algorithm and its application to complete labeling of peak lists from protein NMR spectroscopy. PLoS Comput Biol, 5(3):e1000307, 2009.

[34] Gordon M Crippen, Aikaterini Rousaki, Matthew Revington, Yongbo Zhang, and Erik R P Zuiderweg. SAGA: rapid automatic mainchain NMR assignment for large proteins. J Biomol NMR, 46(4):281-298, 2010.

[35] Erik R P Zuiderweg, Ireena Bagai, Paolo Rossi, and Eric B Bertelsen. EZASSIGN, a program for exhaustive NMR chemical shift assignments of large proteins from complete or incomplete triple-resonance data. J Biomol NMR, 57(2):179-191, 2013.

[36] L E Kay, D A Torchia, and A Bax. Backbone dynamics of proteins as studied by ${ }^{15} \mathrm{~N}$ inverse detected heteronuclear NMR spectroscopy: application to staphylococcal nuclease. Biochemistry, 28(23):8972-8979, 1989.

[37] Giovanni Lipari and Attila Szabo. Model-free approach to the interpretation of nuclear magnetic resonance relaxation in macromolecules. 1. Theory and range of validity. J Am Chem Soc, 104:4546-4559, 1982.

[38] Giovanni Lipari and Attila Szabo. Model-free approach to the interpretation of nuclear magnetic resonance relaxation in macromolecules. 2. Analysis of experimental results. J Am Chem Soc, 104:4559-4570, 1982.

[39] G. Marius Clore, Attila Szabo, Ad Bax, Lewis E. Kay, Paul C. Driscoll, and Angela M. Gronenborn. Deviations from the simple two-parameter modelfree approach to the interpretation of nitrogen-15 nuclear magnetic relaxation of proteins. J Am Chem Soc, 112:4989-4991, 1990.

[40] N A Farrow, R Muhandiram, A U Singer, S M Pascal, C M Kay, G Gish, S E Shoelson, T Pawson, J D Forman-Kay, and L E Kay. Backbone dynamics of a free and phosphopeptide-complexed src homology 2 domain studied by ${ }^{15} \mathrm{~N}$ NMR relaxation. Biochemistry, 33(19):5984-6003, 1994. 
[41] Dmitry M Korzhnev, Nikolai R Skrynnikov, Oscar Millet, Dennis A Torchia, and Lewis E Kay. An NMR experiment for the accurate measurement of heteronuclear spin-lock relaxation rates. J Am Chem Soc, 124(36):1074310753, 2002.

[42] Fabrizio Chiti and Christopher M Dobson. Amyloid formation by globular proteins under native conditions. Nat Chem Biol, 5(1):15-22, 2009.

[43] Pramodh Vallurupalli, Guillaume Bouvignies, and Lewis E Kay. Studying "invisible" excited protein states in slow exchange with a major state conformation. J Am Chem Soc, 134(19):8148-8161, 2012.

[44] Nicolas L Fawzi, Jinfa Ying, Rodolfo Ghirlando, Dennis A Torchia, and $\mathrm{G}$ Marius Clore. Atomic-resolution dynamics on the surface of amyloid- $\beta$ protofibrils probed by solution NMR. Nature, 480(7376):268-272, 2011.

[45] Guillaume Bouvignies and Lewis E Kay. A 2D ${ }^{13} \mathrm{C}-\mathrm{CEST}$ experiment for studying slowly exchanging protein systems using methyl probes: an application to protein folding. J Biomol NMR, 53(4):303-310, 2012.

[46] Pramodh Vallurupalli and Lewis E Kay. Probing slow chemical exchange at carbonyl sites in proteins by chemical exchange saturation transfer NMR spectroscopy. Angew Chem Int Ed Engl, 52(15):4156-4159, 2013.

[47] Alexandar L Hansen, Guillaume Bouvignies, and Lewis E Kay. Probing slowly exchanging protein systems via ${ }^{13} \mathrm{C} \alpha$-CEST: monitoring folding of the Im7 protein. J Biomol NMR, 55(3):279-289, 2013.

[48] Guillaume Bouvignies and Lewis E Kay. Measurement of proton chemical shifts in invisible states of slowly exchanging protein systems by chemical exchange saturation transfer. J Phys Chem B, 116(49):14311-14317, 2012.

[49] Guillaume Bouvignies, Pramodh Vallurupalli, and Lewis E Kay. Visualizing side chains of invisible protein conformers by solution NMR. J Mol Biol, 426(3):763-774, 2014.

[50] Mikael Akke and Arthur G. Palmer. Monitoring macromolecular motions on microsecond to millisecond time scales by $\mathrm{R} 1 \rho$ - $\mathrm{R} 1$ constant relaxation time nmr spectroscopy. Journal of the American Chemical Society, 118(4):911912, 1996.

[51] Francesca Massi, Eric Johnson, Chunyu Wang, Mark Rance, and Arthur G 3rd Palmer. NMR $\mathrm{R}_{1 \rho}$ rotating-frame relaxation with weak radio frequency fields. J Am Chem Soc, 126(7):2247-2256, 2004.

[52] Ivan S Podkorytov and Nikolai R Skrynnikov. Microsecond time-scale dynamics from relaxation in the rotating frame: experiments using spin lock with alternating phase. J Magn Reson, 169(1):164-173, 2004.

[53] Ulrich Weininger, Annica T Blissing, Janosch Hennig, Alexandra Ahlner, Zhihong Liu, Hans J Vogel, Mikael Akke, and Patrik Lundstrom. Protein conformational exchange measured by ${ }^{1} \mathrm{H} \mathrm{R} 1 \rho$ relaxation dispersion of methyl groups. J Biomol NMR, 57(1):47-55, 2013.

[54] Rieko Ishima, Paul T. Wingfield, Stephen J. Stahl, Joshua D. Kaufman, and Dennis A. Torchia. Using amide ${ }^{1} \mathrm{H}$ and ${ }^{15} \mathrm{~N}$ transverse relaxation to 
detect millisecond time-scale motions in perdeuterated proteins: Application to HIV-1 protease. Journal of the American Chemical Society, 120(40):1053410542, 1998.

[55] J. P. Loria, M. Rance, and A. G. Palmer. A relaxation-compensated CarrPurcell-Meiboom-Gill sequence for characterizing chemical exchange by NMR spectroscopy. Journal of the American Chemical Society, 121(10):2331-2332, 1999.

[56] J P Loria, M Rance, and A G 3rd Palmer. A TROSY CPMG sequence for characterizing chemical exchange in large proteins. $J$ Biomol NMR, 15(2):151-155, 1999 .

[57] N. R. Skrynnikov, F. W. Dahlquist, and L. E. Kay. Reconstructing NMR spectra of "invisible" excited protein states using HSQC and HMQC experiments. J Am Chem Soc, 124(41):12352-60, 2002.

[58] H.Y. Carr and E.M. Purcell. Effects of diffusion on free precession in nuclear magnetic resonance experiments. Physical Review, 94(3):630-638, 1954.

[59] S. Meiboom and D. Gill. Modified spin-echo method for measuring nuclear relaxation times. Review of scientific instruments, 29(8):688-691, 1958.

[60] P. Neudecker, P. Lundstrom, and L. E. Kay. Relaxation dispersion NMR spectroscopy as a tool for detailed studies of protein foldingspectroscopy as a tool for detailed studies of protein folding. Biophys J, 96(6):2045-54, 2009.

[61] P. Lundstrom, D. F. Hansen, and L. E. Kay. Measurement of carbonyl chemical shifts of excited protein states by relaxation dispersion NMR spectroscopy: comparison between uniformly and selectively ${ }^{13} \mathrm{C}$ labeled samples. J Biomol NMR, 42(1):35-47, 2008.

[62] V. Y. Orekhov, D. M. Korzhnev, and L. E. Kay. Double- and zero-quantum $\mathrm{nmr}$ relaxation dispersion experiments sampling millisecond time scale dynamics in proteins. Journal of the American Chemical Society, 126(6):18861891, 2004.

[63] P. Lundstrom, D. F. Hansen, P. Vallurupalli, and L. E. Kay. Accurate measurement of alpha proton chemical shifts of excited protein states by relaxation dispersion NMR spectroscopy. J Am Chem Soc, 131(5):1915-26, 2009.

[64] Alexandar L Hansen, Patrik Lundstrom, Algirdas Velyvis, and Lewis E Kay. Quantifying millisecond exchange dynamics in proteins by CPMG relaxation dispersion NMR using side-chain ${ }^{1} \mathrm{H}$ probes. J Am Chem Soc, 134(6):3178$3189,2012$.

[65] P. Lundstrom, K. Teilum, T. Carstensen, I. Bezsonova, S. Wiesner, D. F. Hansen, T. L. Religa, M. Akke, and L. E. Kay. Fractional ${ }^{13} \mathrm{C}$ enrichment of isolated carbons using $\left[1-{ }^{13} \mathrm{C}\right]-$ or $\left[2-{ }^{13} \mathrm{C}\right]$-glucose facilitates the accurate measurement of dynamics at backbone $\mathrm{C} \alpha$ and side-chain methyl positions in proteins. J Biomol NMR, 38(3):199-212, 2007.

[66] P. Lundstrom, H. Lin, and L. E. Kay. Measuring ${ }^{13} \mathrm{C} \beta$ chemical shifts of invisible excited states in proteins by relaxation dispersion NMR spectroscopy. J Biomol NMR, 44(3):139-55, 2009. 
[67] Amy M Ruschak and Lewis E Kay. Methyl groups as probes of supramolecular structure, dynamics and function. J Biomol NMR, 46(1):75-87, 2010.

[68] Jing Xue, David S Burz, and Alexander Shekhtman. Segmental labeling to study multidomain proteins. Adv Exp Med Biol, 992:17-33, 2012.

[69] Garima Jaipuria, B Krishnarjuna, Somnath Mondal, Abhinav Dubey, and Hanudatta S Atreya. Amino acid selective labeling and unlabeling for protein resonance assignments. Adv Exp Med Biol, 992:95-118, 2012.

[70] Donald Voet and Judith G. Voet. Biochemistry. John Wiley \& Sons, Hoboken, NJ, 2011.

[71] Gerhard Gottschalk. Bacterial Metabolism. Springer New York, New York, NY, 1986.

[72] K Pervushin, R Riek, G Wider, and $\mathrm{K}$ Wuthrich. Attenuated $\mathrm{T}_{2}$ relaxation by mutual cancellation of dipole-dipole coupling and chemical shift anisotropy indicates an avenue to NMR structures of very large biological macromolecules in solution. Proc Natl Acad Sci U S A, 94(23):12366-12371, 1997.

[73] N K Goto, K H Gardner, G A Mueller, R C Willis, and L E Kay. A robust and cost-effective method for the production of Val, Leu, Ile $(\delta 1)$ methylprotonated ${ }^{15} \mathrm{~N}-,{ }^{13} \mathrm{C}-,{ }^{2} \mathrm{H}$-labeled proteins. J Biomol NMR, 13(4):369-374, 1999.

[74] Vitali Tugarinov, Ranjith Muhandiram, Ayeda Ayed, and Lewis E Kay. Fourdimensional nmr spectroscopy of a 723-residue protein: chemical shift assignments and secondary structure of malate synthase g. J Am Chem Soc, 124(34):10025-10035, 2002.

[75] Vitali Tugarinov and Lewis E Kay. Ile, leu, and val methyl assignments of the 723-residue malate synthase $\mathrm{g}$ using a new labeling strategy and novel nmr methods. J Am Chem Soc, 125(45):13868-13878, 2003.

[76] M Salzmann, K Pervushin, G Wider, H Senn, and K Wuthrich. TROSY in triple-resonance experiments: new perspectives for sequential NMR assignment of large proteins. Proc Natl Acad Sci U S A, 95(23):13585-13590, 1998.

[77] D Yang and L E Kay. Improved ${ }^{1} \mathrm{HN}$-detected triple resonance TROSY-based experiments. J Biomol NMR, 13(1):3-10, 1999.

[78] J M Scholtz and A D Robertson. Hydrogen exchange techniques. Methods Mol Biol, 40:291-311, 1995.

[79] Paul Schanda, Helene Van Melckebeke, and Bernhard Brutscher. Speeding up three-dimensional protein NMR experiments to a few minutes. $J \mathrm{Am}$ Chem Soc, 128(28):9042-9043, 2006.

[80] V. Y. Orekhov and V. A. Jaravine. Analysis of non-uniformly sampled spectra with multi-dimensional decomposition. Prog Nucl Magn Reson Spectrosc, $59(3): 271-92,2011$. 
[81] T Luan, V Jaravine, A Yee, C H Arrowsmith, and V Yu Orekhov. Optimization of resolution and sensitivity of 4 D NOESY using multi-dimensional decomposition. J Biomol NMR, 33(1):1-14, 2005.

[82] William H. Press. Numerical recipes : the art of scientific computing. Cambridge University Press, Cambridge, UK ; New York, 3rd edition, 2007.

[83] Gunnar Blom. Sannolikhetsteori och statistikteori med tillampningar. Studentlitteratur, Lund, 1989.

[84] Gopal K. Kanji. 100 statistical tests. SAGE Publications, London Thousand Oaks, 2006.

[85] Haiyan Zhang, Stephen Neal, and David S Wishart. RefDB: a database of uniformly referenced protein chemical shifts. J Biomol NMR, 25(3):173-195, 2003.

[86] L C Woodson and R M Weinshilboum. Human kidney thiopurine methyltransferase. purification and biochemical properties. Biochem Pharmacol, 32(5):819-826, 1983.

[87] D. G. Drubin, J. Mulholland, Z. M. Zhu, and D. Botstein. Homology of a yeast actin-binding protein to signal transduction proteins and myosin-i. Nature, 343(6255):288-90, 1990.

[88] M. Mayzel, J. Rosenlow, L. Isaksson, and V. Y. Orekhov. Time-resolved multidimensional NMR with non-uniform sampling. J Biomol NMR, 58(2):12939, 2014.

[89] S. Wiesner, L. E. Wybenga-Groot, N. Warner, H. Lin, T. Pawson, J. D. Forman-Kay, and F. Sicheri. A change in conformational dynamics underlies the activation of Eph receptor tyrosine kinases. EMBO J, 25(19):4686-96, 2006 .

[90] L. E. Wybenga-Groot, B. Baskin, S. H. Ong, J. Tong, T. Pawson, and F. Sicheri. Structural basis for autoinhibition of the EphB2 receptor tyrosine kinase by the unphosphorylated juxtamembrane region. Cell, 106(6):745-57, 2001.

[91] J. P. Himanen, N. Saha, and D. B. Nikolov. Cell-cell signaling via Eph receptors and ephrins. Curr Opin Cell Biol, 19(5):534-42, 2007.

[92] M. Lackmann, A. C. Oates, M. Dottori, F. M. Smith, C. Do, M. Power, L. Kravets, and A. W. Boyd. Distinct subdomains of the EphA3 receptor mediate ligand binding and receptor dimerization. J Biol Chem, 273(32):2022837, 1998.

[93] S. H. Wimmer-Kleikamp, P. W. Janes, A. Squire, P. I. Bastiaens, and M. Lackmann. Recruitment of Eph receptors into signaling clusters does not require ephrin contact. J Cell Biol, 164(5):661-6, 2004.

[94] F. M. Smith, C. Vearing, M. Lackmann, H. Treutlein, J. Himanen, K. Chen, A. Saul, D. Nikolov, and A. W. Boyd. Dissecting the EphA3/Ephrin-A5 interactions using a novel functional mutagenesis screen. $J$ Biol Chem, 279(10):9522-31, 2004. 
6.

[95] F. Qiao and J. U. Bowie. The many faces of SAM. Sci STKE, 2005(286):re7, 2005.

[96] O Glatter. Small angle x-ray scattering. Academic Press, London New York, 1982. 
Chapter 7

\section{Papers}


7. 


\section{Papers}

The articles associated with this thesis have been removed for copyright reasons. For more details about these see:

http://urn.kb.se/resolve?urn=urn:nbn:se:liu:diva-117076 